\title{
Prevention of hyper- and hypotrophic scars through surgical incisions in the direction of the "main folding lines" of the skin
}

\author{
Gottfried Lemperle \\ Division of Plastic Surgery, University of California, San Diego, CA 92103-8890, USA. \\ Correspondence to: Prof. Gottfried Lemperle, Plastic Surgeon, Wolfsgangstr. 64, Frankfurt am Main D-60322, Germany. \\ E-mail: lemperle8@aol.com
} How to cite this article: Lemperle G. Prevention of hyper - and hypotrophic scars through surgical incisions in the direction of the
"main folding lines" of the skin. Plast Aesthet Res 2020;7:40. http://dx.doi.org/10.20517/2347-9264.2020.14

Received: 30 Apr 2019 First Decision: 1 Jun 2020 Revised: 17 Jun 2020 Accepted: 20 Jun 2020 Published: 26 Jul 2020

Academic Editor: Alexis Desmoulière, Jérôme Laloze Copy Editor: Cai-Hong Wang Production Editor: Jing Yu

\begin{abstract}
Langer's lines are still the recommendation and matrix for surgical incisions in most surgical textbooks, even if they were never meant to be by their first describer in 1861. To achieve minimal scarring, surgeons should attempt to make incisions parallel to skin tension lines, i.e., in skin folds or skin creases. On the basis of visible stretch marks (striae distensae) in the skin, which always appear in the same direction against skin tension in men and women, the direction of skin tension lines can be manifested also in the skin of children and young patients. These invisible or virtual tension lines are the same as the main folding lines (MFL) in adults and run perpendicular to the stretch marks. While well-established on the face and abdomen, these folding lines may not be obvious on other parts of the body. On chest, back and extremities, optimal direction of surgical skin incisions should take into account the patterns of striae distensae, which develop perpendicular to skin tension lines. MFL should be used in elective incisions in children, adolescents, and young women as a guide for the prevention of later visible hyper- or hypotrophic scars.
\end{abstract}

Keywords: Surgical incisions, folding lines, skin tension lines, Langer's lines, striae distensae, stretch marks, hypertrophic scar

\section{INTRODUCTION}

Minimally invasive and endoscopic surgeries have revolutionized thoracic, abdominal, and orthopedic surgery, and have become today's gold standard, resulting in much smaller scars. However, children and 

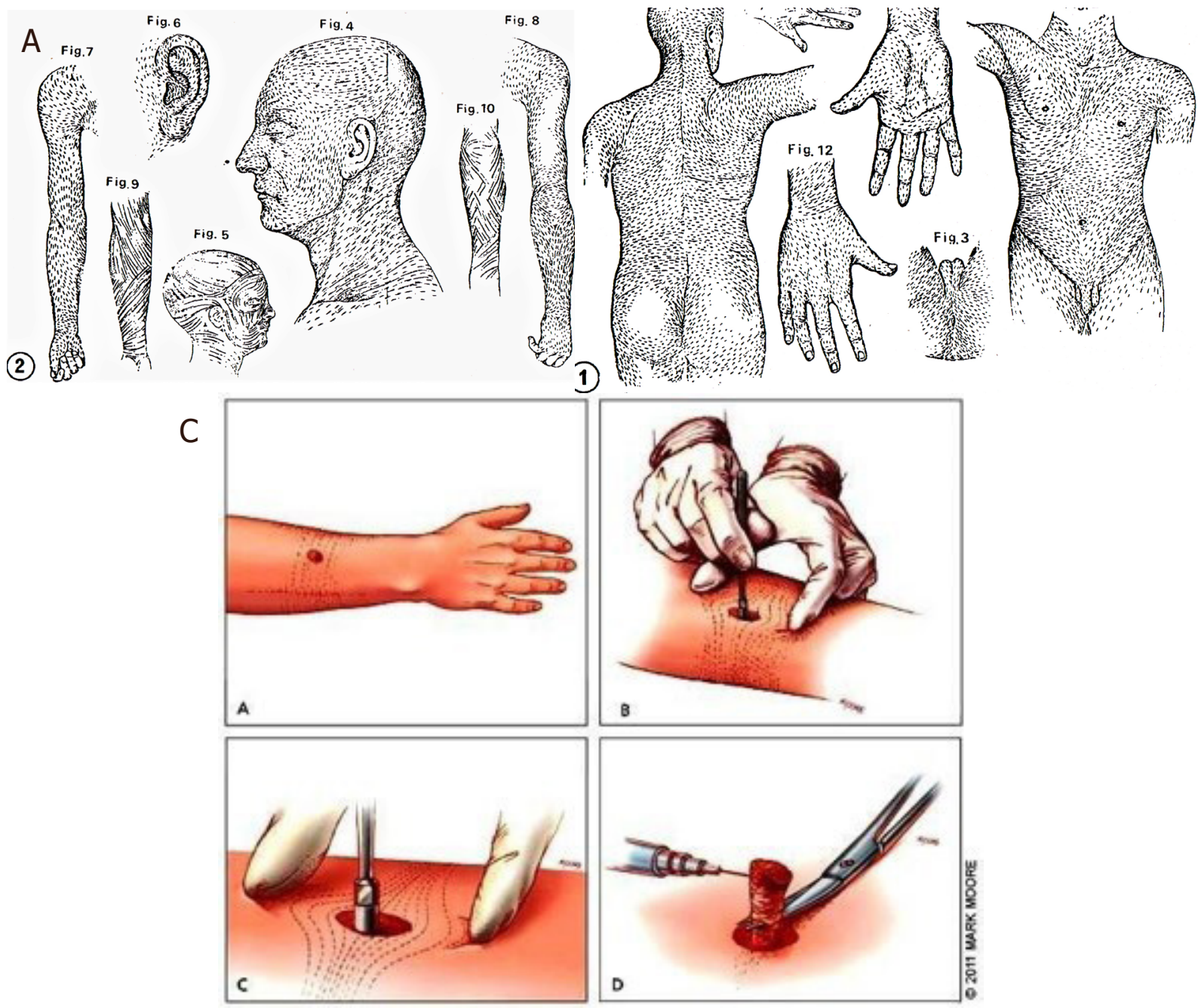

Figure 1. Some Langer's "cleavage lines" run oblique or perpendicular to the recommended "main folding lines" on forehead, lower abdomen, buttocks and extremities (A); on the other hand, some Langer's cleavage lines run parallel to the "main folding lines" over neck, shoulders, upper abdomen and back and therefore correctly in the direction of the proposed "tension lines" (B) (both figures are reproduced with permission from Lemperle et $a{ }^{\left[{ }^{[11]}\right.}$.); langer punched round holes into cadaver skin at various sites to determine invisible "cleavage lines" (C) (Drawings by Mark Moore 2011)

adolescents are still prone to develop hypertrophic scars, which could be prevented by surgical incisions in the direction of the main folding lines (MFL) of the skin. The list of ineffective treatments for scars is long, including heparin, panthenol and silicone creams, needling rollers, and laser therapy. However, pressure dressings and corticosteroid injections are the only effective treatments in fresh and surgical excision of mature hypertrophic scars, while injectable dermal fillers can be used in broad indented hypotrophic scars.

Surgical and orthopedic textbooks do not mention natural folding lines for optimal surgical incisions. The purpose of this review is to facilitate the determination of optimal incision lines perpendicular to the direction of striae distensae.

\section{History of surgical incision lines}

When consulted to correct conspicuous scars from prior surgeries, some surgeons still rely on Langer's invisible "cleavage lines" described in $1861^{[1]}$, which run perpendicular to skin folds in several regions of the body [Figure 1A and B]. However, folds and folding lines are easily determined in adults by bending a joint or pinching the skin in different directions. 

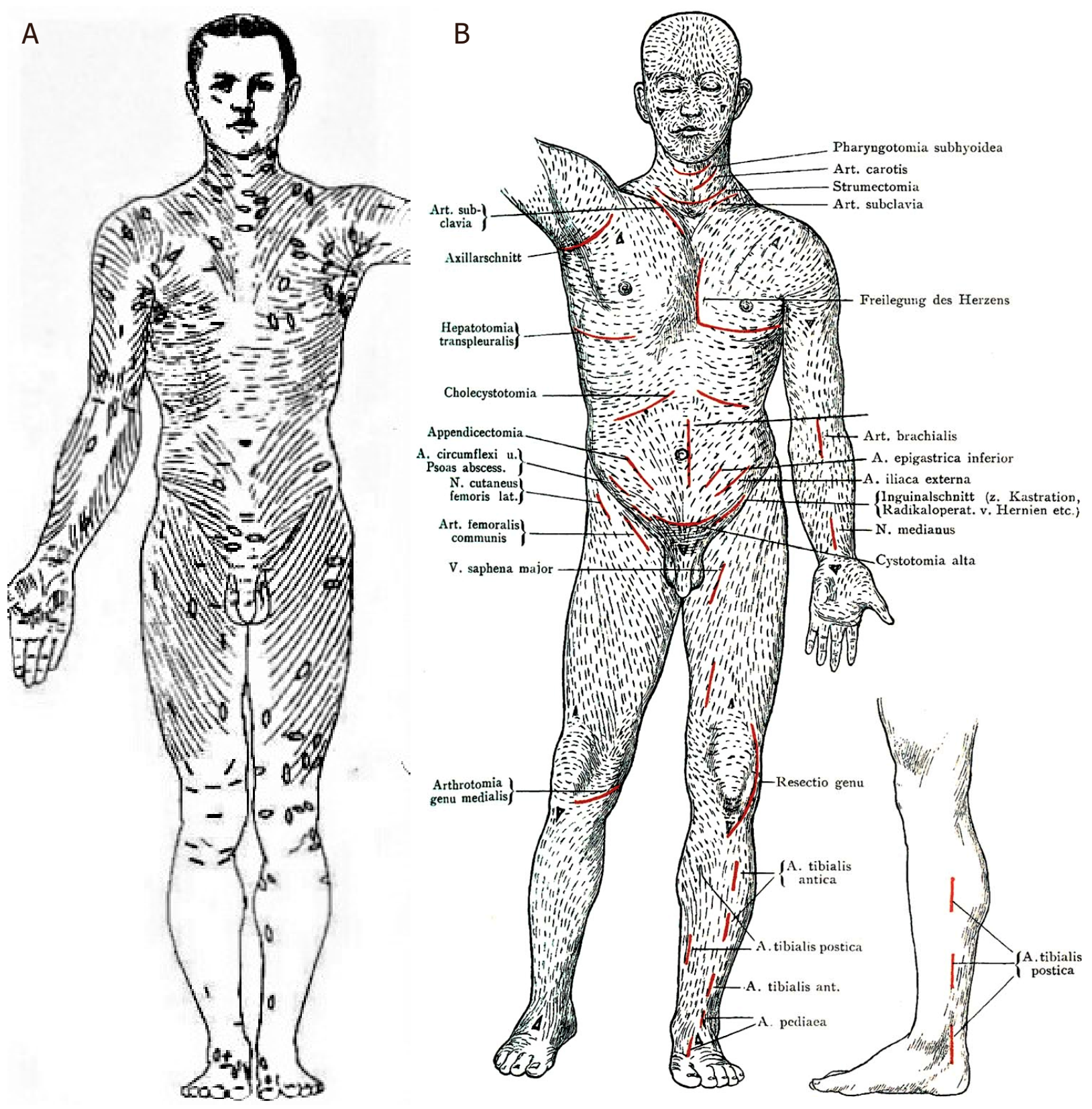

Figure 2. As early as 1892 , Kocher recommended "Langer's cleavage lines" for all surgical excisions and incisions (A); especially on extremities of children and adolescents, the lengthwise running scars often become hypertrophic (B) (both figures are reproduced with permission from Lemperle et al. ${ }^{[11]}$ )

Langer, an anatomist in Vienna, Austria, had no surgical incisions in mind during his well-known experiments on cadaver skin. After punching round holes into cadaver skin, he suggested the best direction of the wound margins by invisible "cleavage lines", which eventually became oval-shaped ${ }^{[1]}$ [Figure $\left.1 \mathrm{C}\right]$. In 1892 Kocher, a famous surgeon and Nobel laureate in Bern, Switzerland, promoted Langer's lines worldwide as direction for skin excisions and incisions ${ }^{[2]}[$ Figure $2 \mathrm{~A}$ and $\mathrm{B}]$.

To achieve minimal scar formation, surgical incisions must be placed in "main folding lines" ${ }^{\text {"3-5] }}$ [Figure $3 \mathrm{~A}$ and B] or in the also invisible "relaxed skin tension lines" of Borges ${ }^{[6-8]}$. Although facial and abdominal folds can be easily identified, folding lines may be difficult to determine on the back, arms and legs, and may 
A
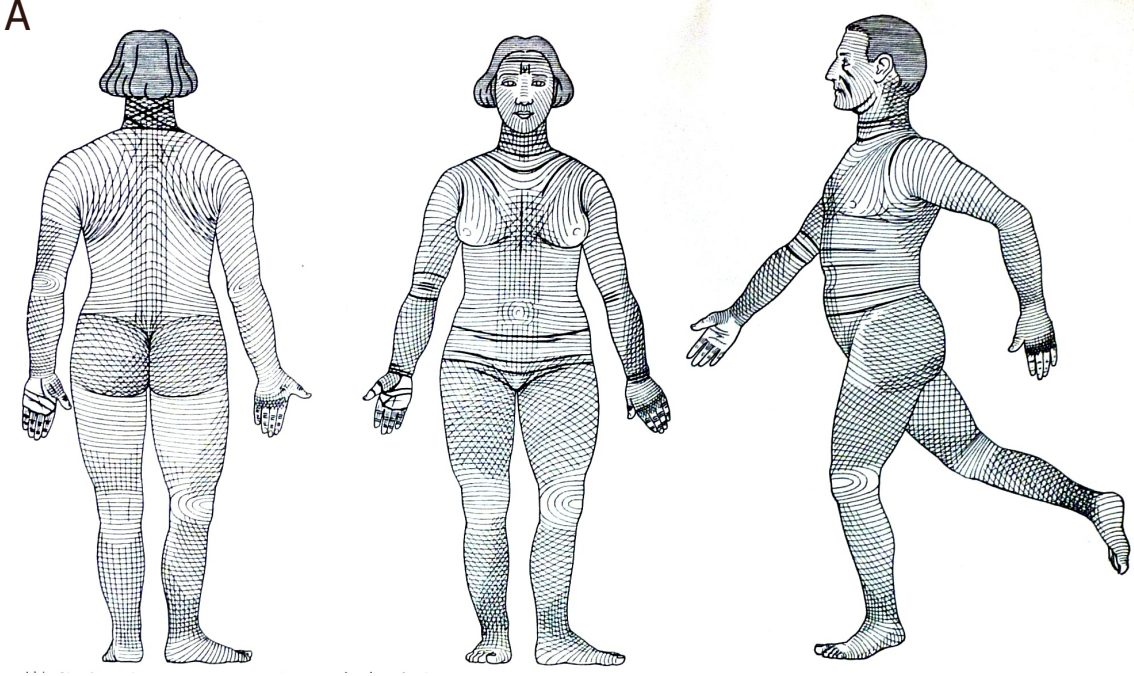

B
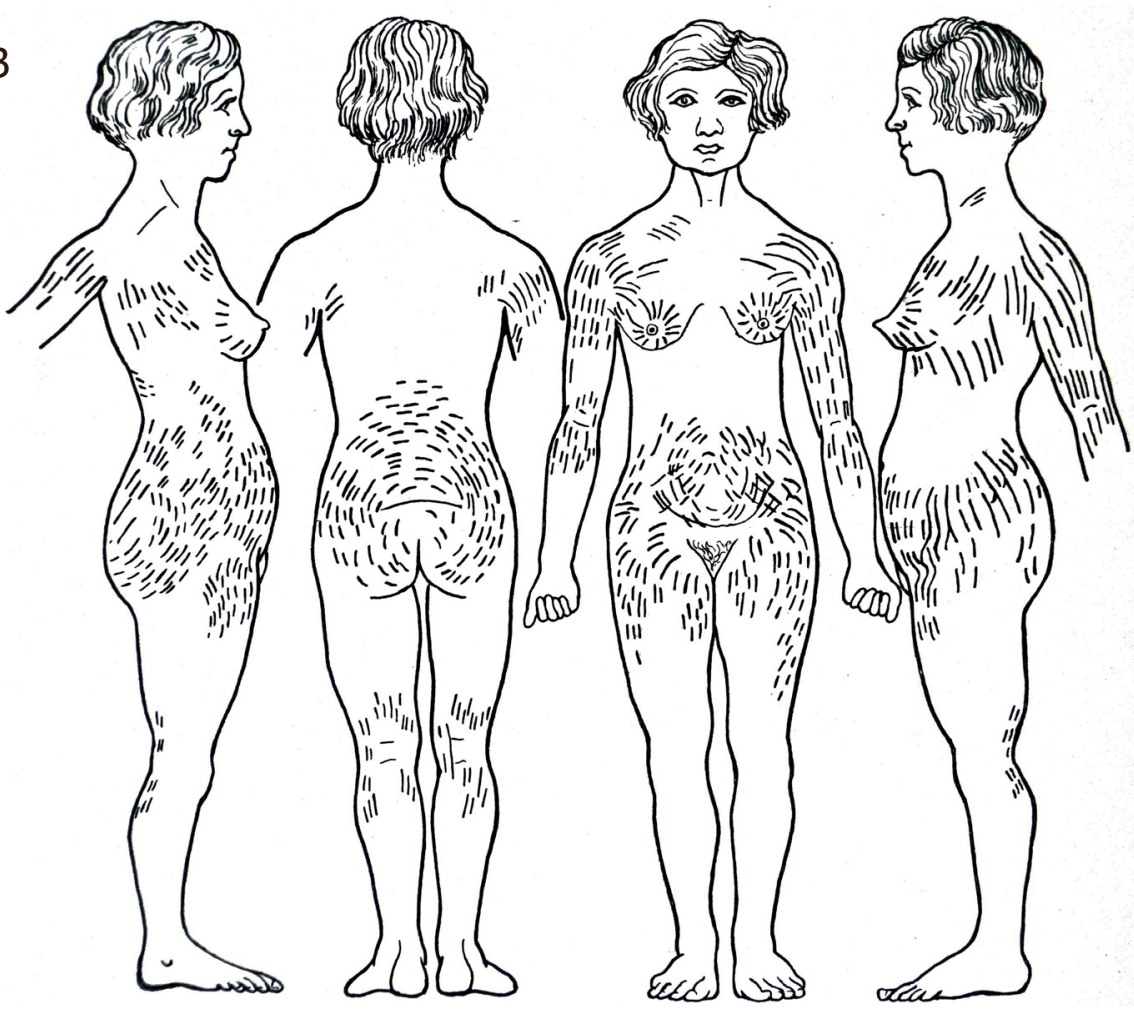

Figure 3. Pinkus' "main folding lines" (MFL) of the skin facilitate optimal incision lines. These drawings, however, are irritating to a surgeon because they are not clearly defined at the extremities (A); a drawing of collected striae gravidarum by Pinkus in 1927 (B) (both figures are reproduced with permission from Lemperle et al. ${ }^{[11]}$ )

be absent in younger patients. Interestingly, the stripes of tigers and zebras, and the folds in Sharpei dogs follow similar lines, transverse at the torso and extremities, and concentric towards the inner side of large joints.

Aesthetic surgeons learn to follow specific directions for incisions, and reconstructive surgeons may be uncertain of the optimal direction. General surgeons focus on the fastest and most direct way to reach the abdominal cavity, while orthopedic surgeons focus on the most convenient way to access a bone or joint. Surgical and orthopedic textbooks do not mention natural folding lines for optimal incisions ${ }^{[9,10]}$. The 

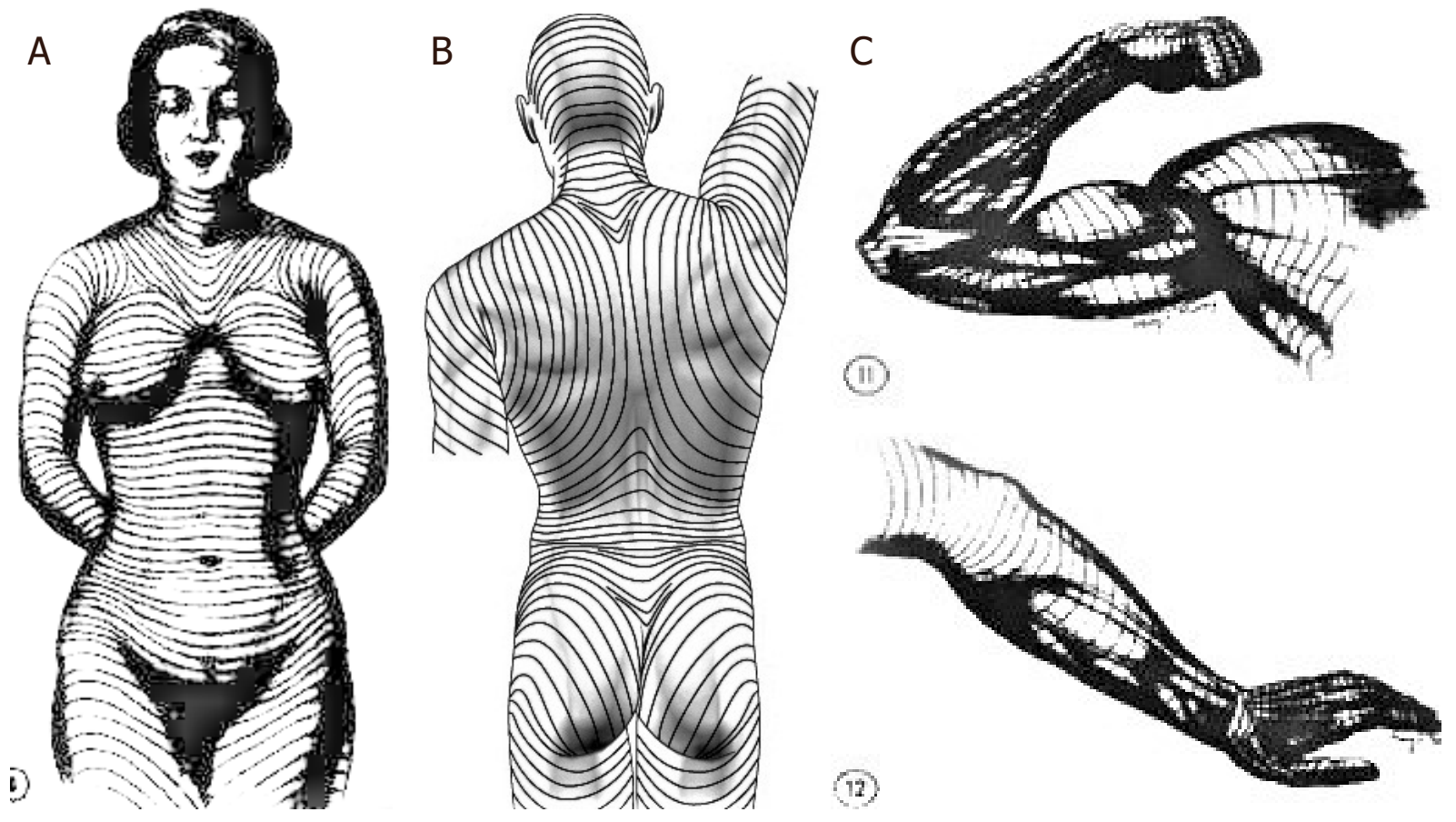

Figure 4. Kraissl's lines (1954) run perpendicular to the direction of underlying muscles but are not correct over breasts, lower back and buttocks (A-C) (these figures are reproduced with permission from Lemperle et al. ${ }^{[11]}$ )

concept of using natural striae distensae for optimal incision lines is new ${ }^{[11]}$ and an extension of the earlier presentations of Kraissl ${ }^{[4,5]}$ and Borges ${ }^{[6-8]}$.

During the past century, thirty-eight various guidelines have been developed regarding elective skin incisions ${ }^{[6,12]}$. Most surgical textbooks include Kraissl's "incisions perpendicular to muscle action" of $1951^{[5]}$ [Figure $4 \mathrm{~A}-\mathrm{C}$ ] or Langer's "cleavage lines" of $1861^{[1,12,13]}$ [Figure $1 \mathrm{~A}$ and $\mathrm{B}$ ], despite the fact that these incisions run oblique or even perpendicular to skin folds on the forehead, cheeks, breasts, and abdomen. They run vertically across the antecubital region, the wrist, thigh, and distal regions of the extremities, although concordant on the neck, shoulders, back and buttocks. Therefore, new oblique, horizontal or partly circumferential directions for incisions on extremities have to be proposed.

In 1927, dermatologist Felix Pinkus was the first to question Langer's lines as a guide for skin incisions, and he described the "main folding lines" [Figure $3 \mathrm{~A}$ ] as the ideal direction for elective incisions ${ }^{[3]}$. He also described and illustrated the location of striae [Figure $3 \mathrm{~B}$ ], but did not relate them to skin incisions. The publication in a German dermatological textbook ${ }^{[3]}$ did not reach the surgical community.

In the 1950s, Cornelius Kraiss ${ }^{[4,5]}$ proposed lines oriented perpendicular to the action of the underlying muscles [Figure $4 \mathrm{~A}-\mathrm{C}$ ] by demonstrating histologically that the adherent connective tissue bands run from the skin to the underlying fascia, perpendicular to the long axis of the muscles, especially at joints such as wrist and knee. His drawing of the facial folds shows long-accepted incision lines on the face.

In 1962, Alberto Borges ${ }^{[6,7]}$ described the "relaxed skin tension lines" (RSTL) on the face and in 1984 on the body ${ }^{[8]}$. RSTL follow furrows produced by pinching the skin in different directions - which had been recommended earlier by Pinkus ${ }^{[2]}$ and Kraiss ${ }^{[4]}$.

This "pinching", however, is difficult to practice on the back and extremities of younger patients, especially on the forearm in both, the supine and pronate position $)^{[14]}$. Courtiss in $1963^{[15]}$ and Barile in $1976^{[16]}$ 

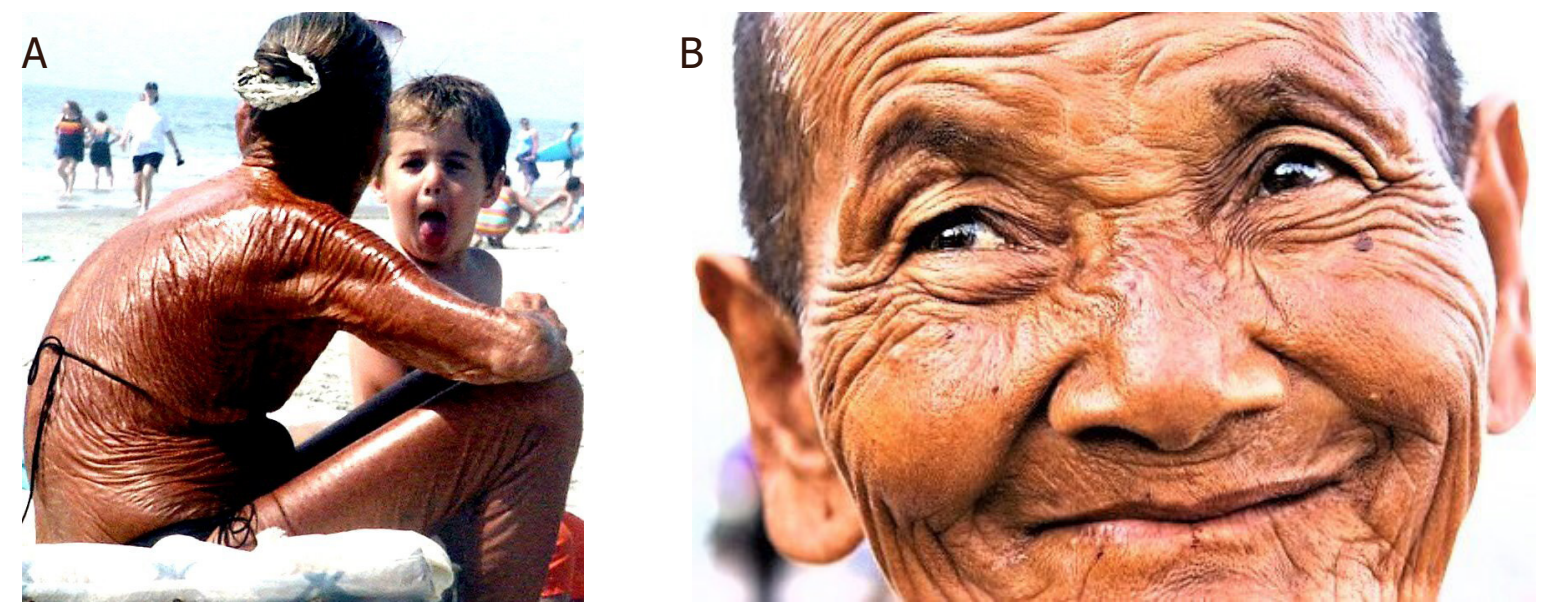

Figure 5. If all patients presented with these clear folding lines, the choice of skin incisions would be easy ( $A$ and $B$ )
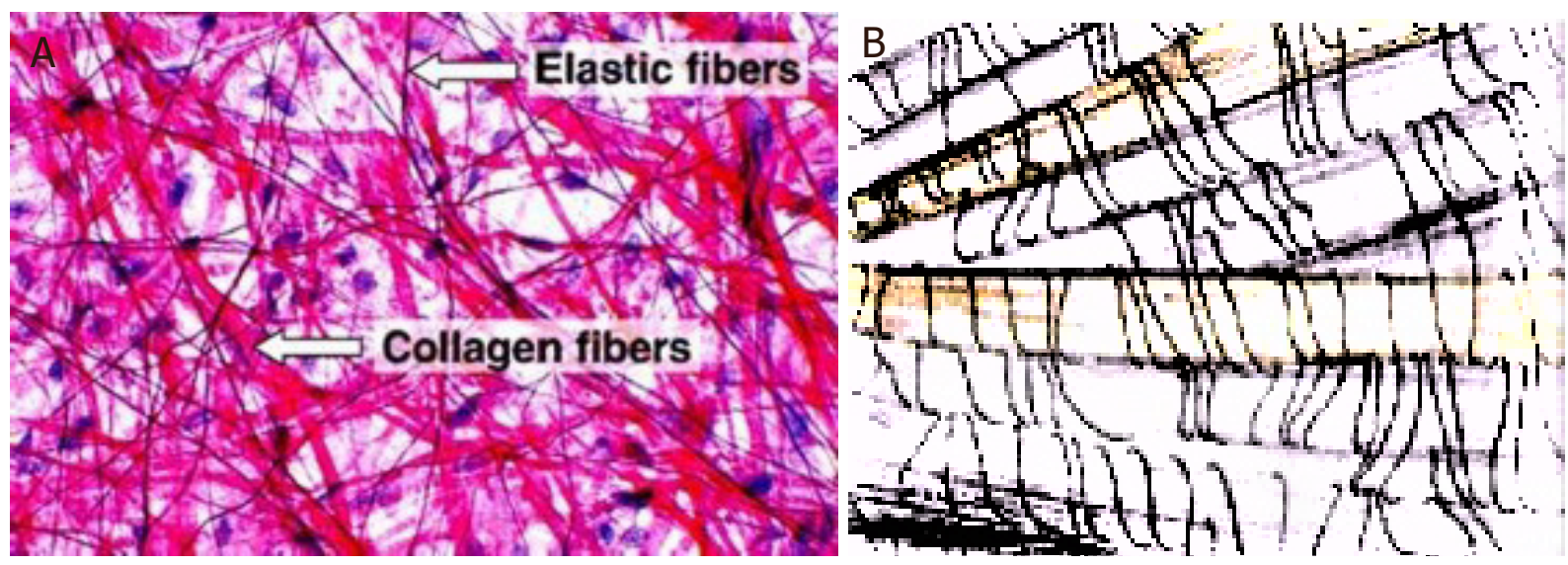

Figure 6. The network of fibers in the dermis will be compressed beneath a skin fold. The transverse elastic fibers will remain together with the parallel collagen fibers; those diagonal to the fold will be displaced or absorbed as the fold deepens (A and B) (EM of R. Roth, Tübingen)

essentially copied the article and illustrations of Kraiss ${ }^{[4]}$ and recommended, just like Borges ${ }^{[8]}$, to follow Kraissl's lines for the rest of the body.

Uncertainty about the best direction of surgical incisions led to more proposals. Carmichael ${ }^{[13]}$ used a "Reviscometer" to measure electrical waves travelling radially on the skin, and Paul ${ }^{[17,18]}$ recommended a bi-directional "Tensiometer", a type of broad plastic forceps connected to an electrical indicator to measure skin tension. There appears to be no practical value, as nature already presents skin tension lines as folds in elderly patients [Figure 5A and B] or as striae distensae in many younger ones.

\section{Histology of tension lines}

The presence of tension lines and normal wrinkle lines in the skin depends on the interrelation between elastic fibers and collagen fibers, as well as on the anchorage of collagen bundles one upon another ${ }^{[19]}$ [Figure 6A and B]. While collagen fibers underlying Langer's cleavage lines are arranged irregularly and interweaving, they are lined up parallel beneath folds in their direction.

The fibroblasts in striae possess a contractile phenotype more akin to myofibroblasts ${ }^{[19,20]}$, and the elastic fiber network proximal to the epidermal- dermal junction appears to be more prone to destruction in 


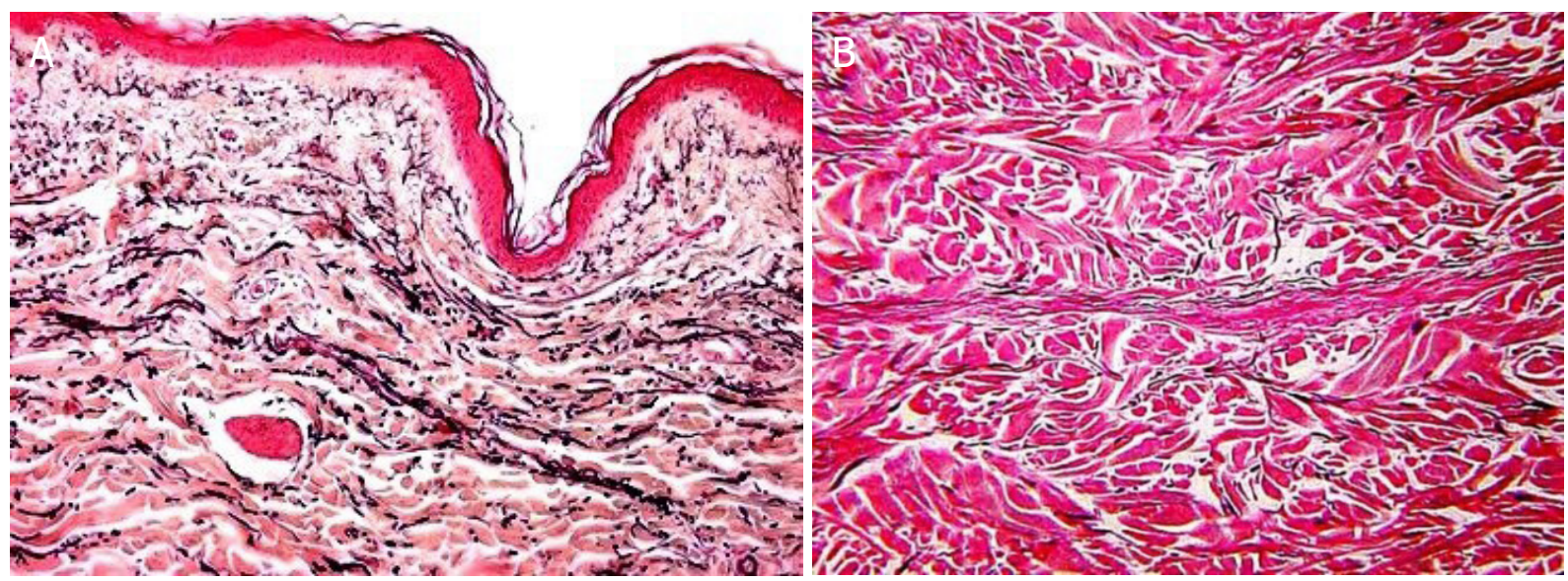

Figure 7. A skin fold with reduced collagen fibers underneath but compressed elastic fibers (black) running diagonal to the fold. The collagen fibers are mainly running parallel to the fold but cut across the fold ( $A$ and $B$ )

active striae. The collagen lattice can be ruptured under the influence of steroids and especially estrogens. The newly synthesized collagen becomes reorganized by tension and is aligned in the direction of the presumed stress. The same happens in wound healing, and therefore, striae are considered dermal scars ${ }^{[21,2]}$ [Figure $7 \mathrm{~A}$ and $\mathrm{B}$ ].

\section{Striae distensae}

Striae distensae or striae gravidarum are seen in many patients and can often act as a guide in planning elective incisions. Regardless of their etiology and slight variation, they have the same direction and clinical appearance [Figure $3 \mathrm{~A}$ and $\mathrm{B}]$.

The fibroblasts in striae possess a contractile phenotype more akin to myofibroblasts ${ }^{[19,20]}$ and the elastic fiber network proximal to the epidermal- dermal junction appears to be more prone to destruction in active striae. The collagen lattice can be ruptured under the influence of steroids and especially estrogens. The newly synthesized collagen becomes reorganized by tension and is aligned in the direction of the presumed stress. The same happens in wound healing, and therefore, striae are considered dermal scars ${ }^{[21,22]}$.

Striae distensae are characterized by linear, smooth bands of atrophic skin that are reddish at first and ultimately turn pale. In young adolescents, they can appear during growth spurts on hips, inner thighs, and female breasts, as well as on the shoulders, lower back, and outer thighs of boys without measurable changes in their hormone levels ${ }^{[22]}$ [Figures 8-11]. Eighty percent of adolescents in Korea show striae: in girls more pronounced on the buttocks, thighs and calves, and in boys on the buttocks, knees and lower $\operatorname{back}^{[23]}$.

During pregnancy, striae distensae appear in the abdominal skin often during the first months of pregnancy and before tension is caused by the growing fetus and uterus. Obesity, oral contraceptives, and breast augmentation can also cause striae in a small percentage of women ${ }^{[24]}$. The widest and deep red striae are seen in Cushing patients and in those under chronic systemic or local cortisone therapy ${ }^{[2,26]}$ [Figure 12].

Women with pelvic relaxation and prolapse demonstrate striae twice as often as healthy women. There appears to be a strong association between the presence of striae, varicosis, and the development of pelvic relaxation $^{[27]}$; genetically weak connective tissue appears to be the reason for all three deformities ${ }^{[28]}$.

The claim of mechanical stretching being the main cause of striae is disputable: striae often occur in early pregnancy when there is no obvious skin stretching by the growing uterus. They also appear over the hips 

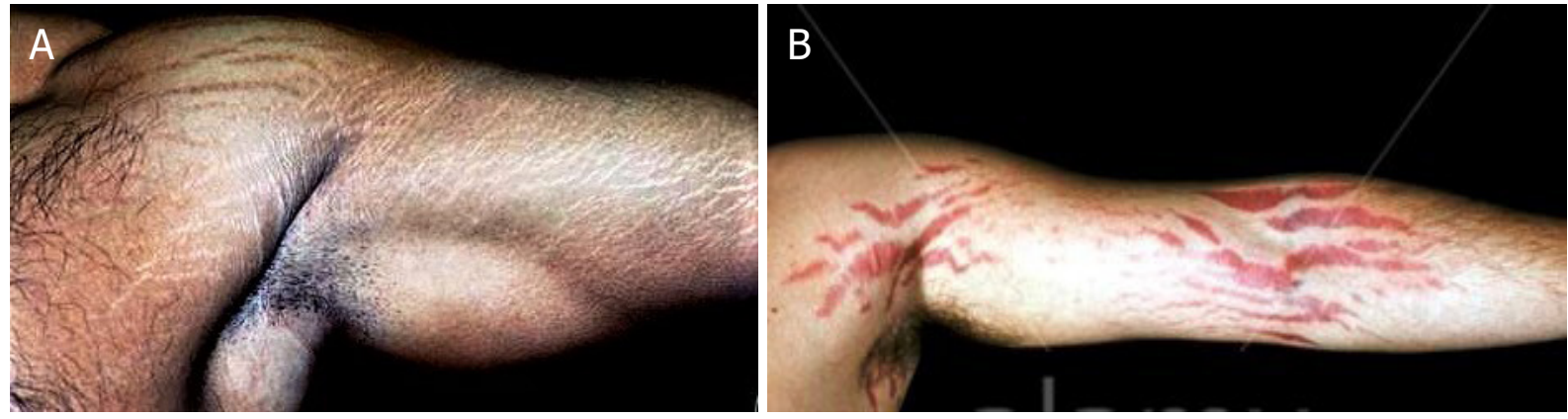

Figure 8. Striae in a body builder and a Cushing patient run parallel to the direction of the muscle bundles: therefore, all incisions on extremities should be made oblique but should not interfere with major nerves and arteries ( $A$ and $B$ )
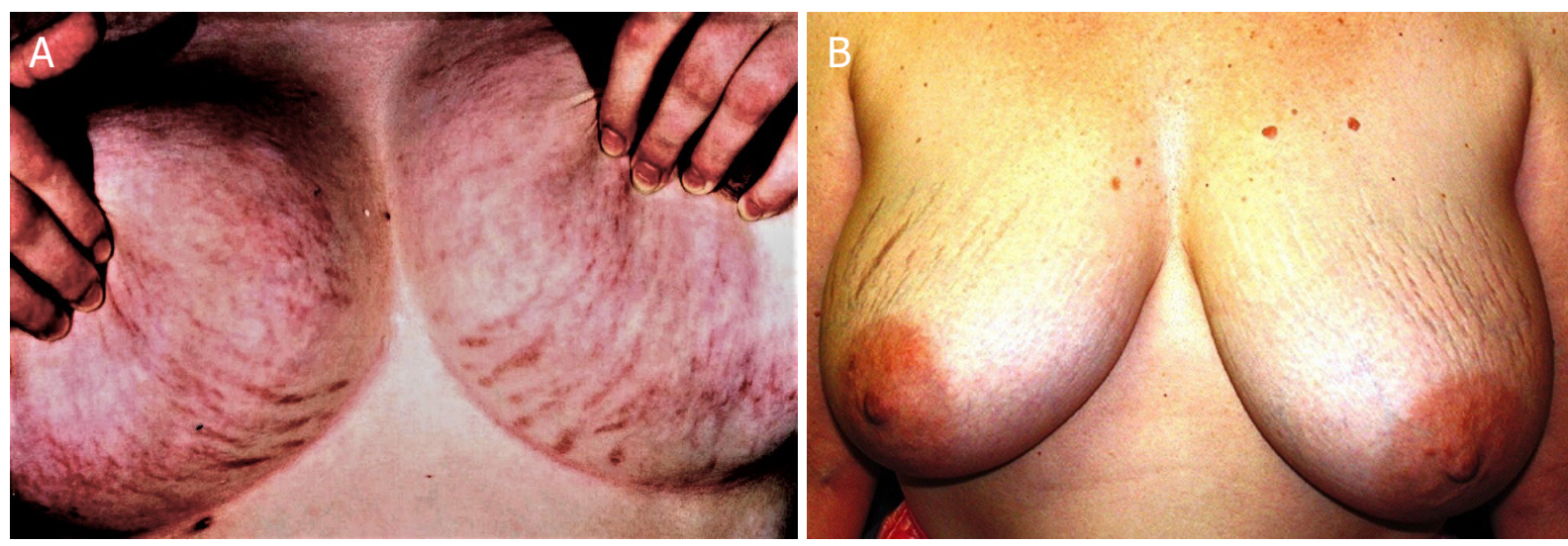

Figure 9. Radial fresh striae on the breasts during pregnancy and mature striae postpartum ( $A$ and $B$ )
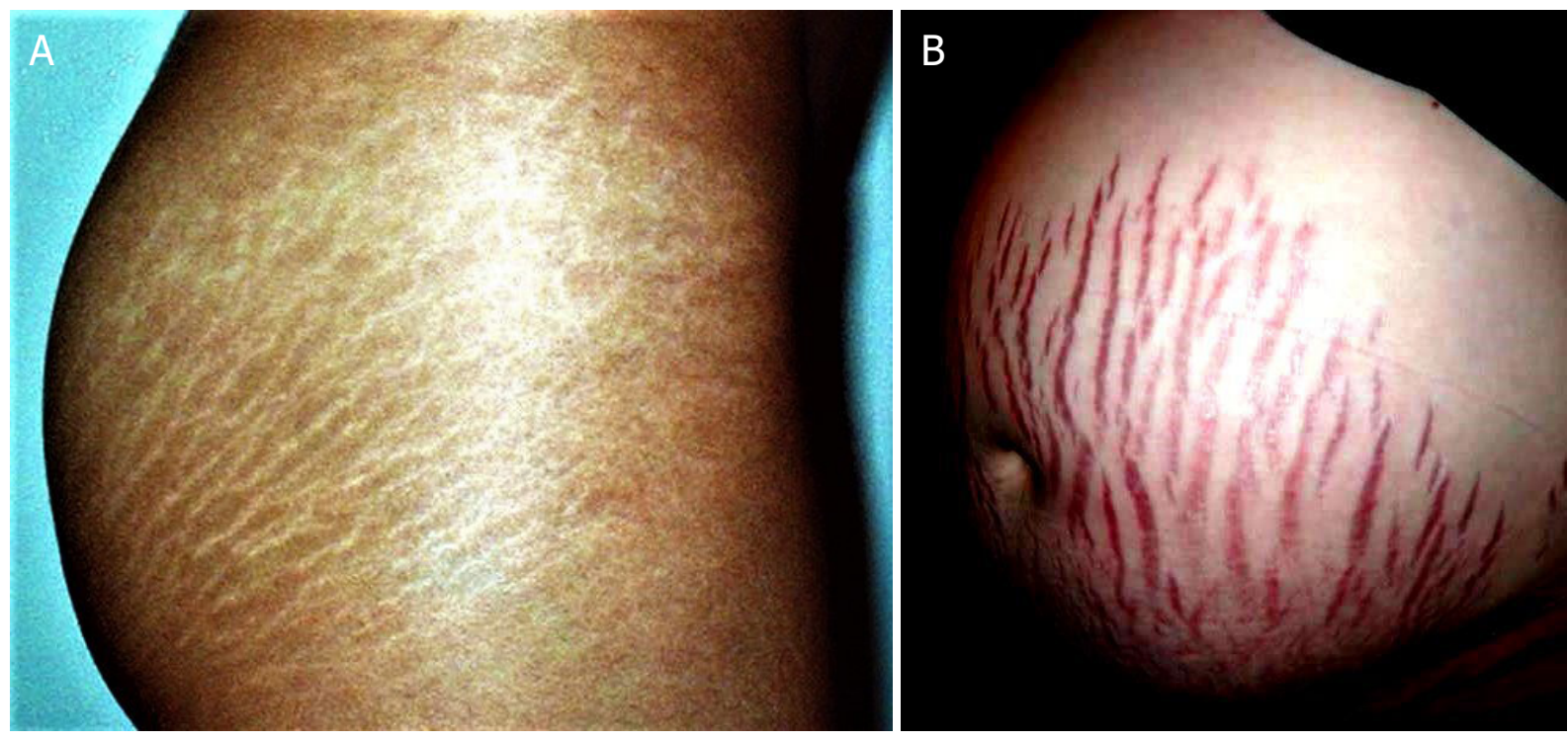

Figure 10. As an exception, striae distensae over the buttocks run perpendicular to the muscle fibers of the underlying gluteus major muscle (A and B) (Figure 10A is reproduced with permission from Lemperle et al. ${ }^{[1]}$ )

of adolescents, where there is little stretching during the day or sleep. If skin expansion is the only reason, the use of inflatable silicone expanders should be accompanied by a certain incidence of striae formation, but it is not. 

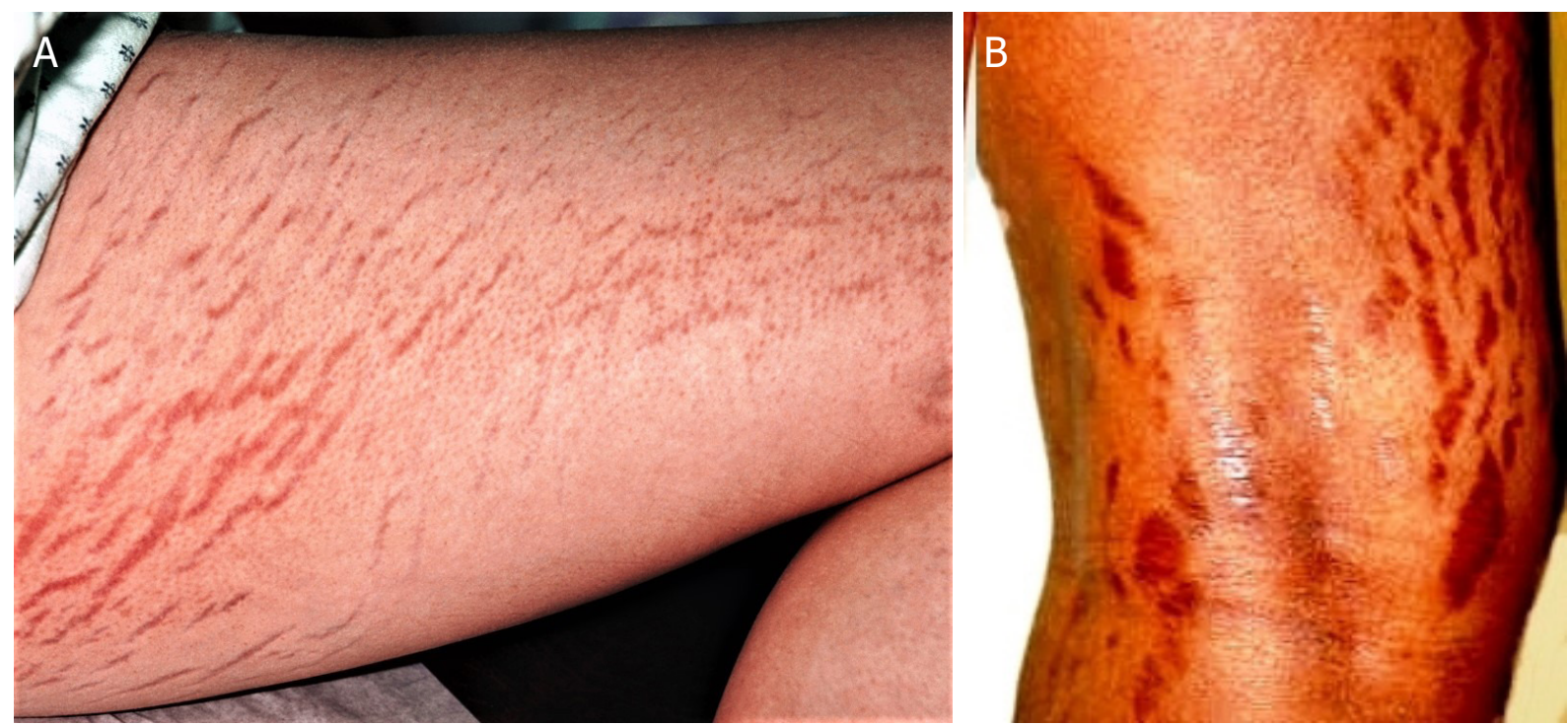

Figure 11. Striae on the inner thigh run oblique and vertical over the knee joint; therefore, incisions should be made perpendicular to them, i.e., horizontally in the popliteal groove (A and B) (Figure 11A is reproduced with permission from Lemperle et al. ${ }^{[11]}$ )
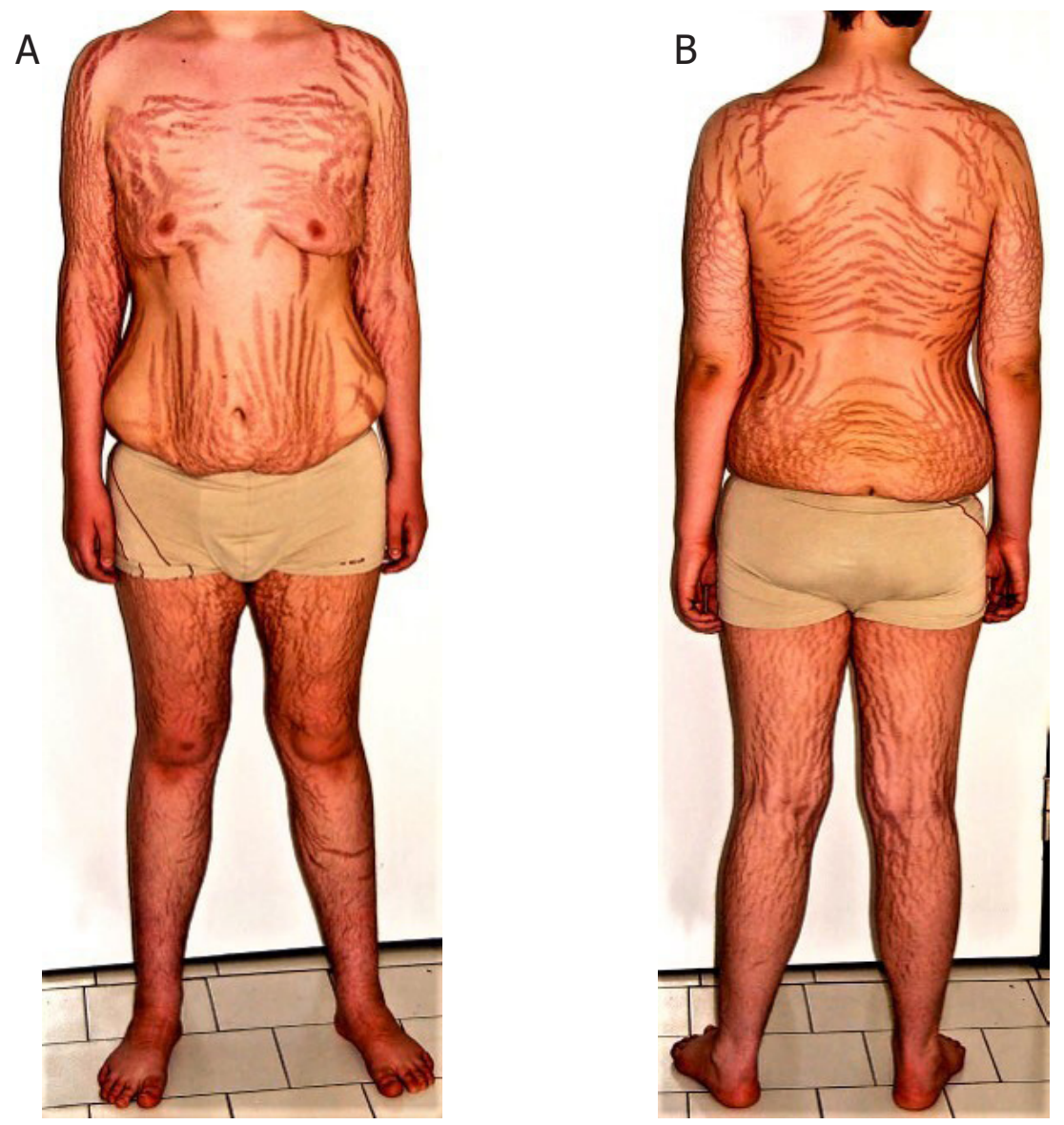

Figure 12. Extreme striae distensae in a 14-year-old boy with encephalitis, treated with common doses of dexamethasone over 9 months $(A$ and $B)$ (both figures are reproduced with permission from Lemperle et al. ${ }^{[1]}$ ) 
Also, if excessive skin stretching were a factor, athletes, gymnasts, and heavy-lifting workers would be expected to develop more stretch marks than the average population. Yet, the only athletes known to develop them are weightlifters and probably due to the use of anabolic steroids. In general, potential causes for striae development are family history, difficult hormonal equilibrium during adolescence, obesity, and the presence of varicosis ${ }^{[29]}$.

Recent research on estrogen receptors in the extracellular matrix suggests the importance of estrogen in the development of striae ${ }^{[30]}$. When estrogen, androgen and glucocorticoid receptors in the skin of patients with striae were compared to those in healthy skin, their number was actually double ${ }^{[31]}$. These findings indicate that under certain conditions, there is an increase in hormone receptor expression in the skin. Hormone receptor activity may influence the metabolism of the extracellular matrix, pointing to the important involvement of estrogens in striae formation.

In general, people with a lack of elastic components in the extracellular matrix of their dermis are more prone to hypotrophic than hypertrophic scar formation. To date, there still remains a lack of logical and effective, evidence-based treatments for stretch marks, including non-surgical skin tightening procedures, such as laser treatments or topical preparations that claim "collagen remodeling"

\section{MATERIALS, METHODS, RESULTS}

A total of 213 photographs of patients with striae as adolescents were examined, during and after pregnancy, diagnosed with "linear focal elastosis" ${ }^{\text {"[3,34] }}$ and after Cushing's disease or steroid use and abuse. Sources included our own image files (78 photographs) as well as an extensive Google search on "stretch marks" and "striae" (135 photographs). All relevant striae were copied onto blank templates and 3 overall direction charts were created [Figure 13A]. Regardless of their etiology, all striae demonstrated a similar clinical appearance and same direction in both male and female skin. Furthermore, the direction of the lamellae in patients with linear ichthyosis was the same as the skin's MFL across the entire body ${ }^{[35]}$.

Optimal incision lines were established from a slide collection of the Department of Plastic Surgery at Markus Hospital in Frankfurt/Main, Germany, including hundreds of surgical scar corrections from the past 50 years. Each direction of a "right or wrong" incision was compared with the direction of the folding lines and judged either "optimal" within the MFL, or "suboptimal", if the scar was hypertrophic or wider than expected. In addition, 276 images of unknown surgical incisions and scars were retrieved from the Internet, and their direction and width were compared to the MFL.

Photographs of striae did not include all regions of the body. The logical elongation of the direction of striae over the front of the lower leg was retrieved from the folding lines of elderly patients and patients with linear ichthyosis. In children and adolescents, the main skin folding lines on the face, neck, hand and foot were found in skin folds by moving the head or limbs.

The striae-derived tension or MFL [Figure 13B] were consistent with the direction of Kraissl's lines on the shoulder, chest, abdomen, arms and legs, but not on the breasts, lower back, and buttocks, where they run parallel to the muscle fibers of the gluteus maximus muscle. However, they disproved Langer's lines on the lower abdomen, back, buttocks, posterior thigh, and foot, but coincided with Langer's lines on the upper back, chest, upper abdomen, anterior thigh, knee, and lower leg.

Alternatively, Pinkus ${ }^{[3]}$ described several directions of skin folding lines over body and limbs [Figure 4], rather than an ideal direction for surgeons to follow. Striae distensae follow the natural anti-tension lines of the skin of all ages and races and are therefore an objective indicator for the direction of the real tension lines, e.g., always perpendicular to them. 

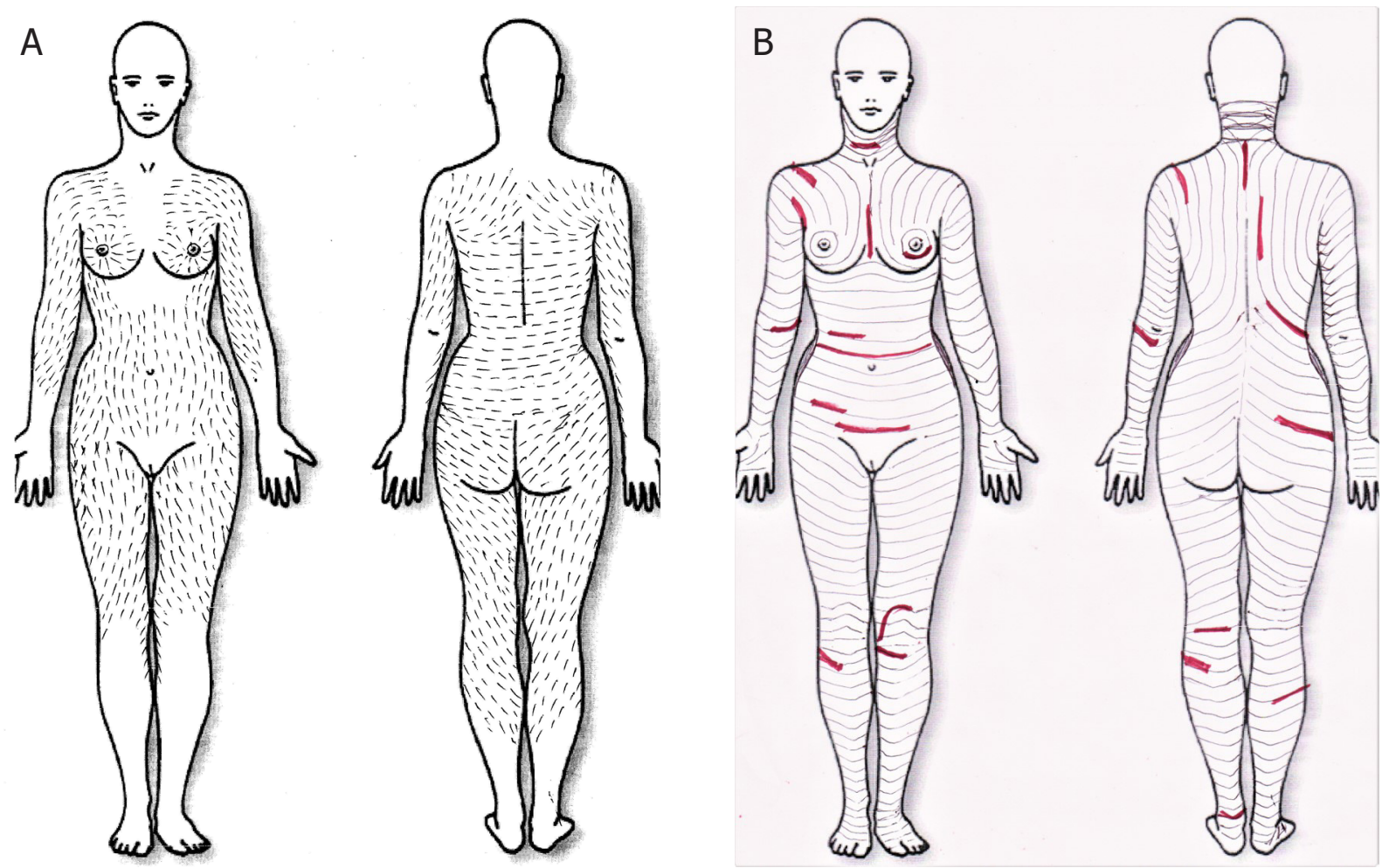

Figure 13. A compound of striae lines collected from 213 photographs of patients with different underlying etiology. The resulting "main folding lines" (MFL) run perpendicular to the striae lines (A and B)

\section{"Pinch test"}

The "pinch test" ${ }^{[3]}$ is an easy and practical tool to find the "main folding lines" in old and middle-aged people, but less valuable in children and adolescents. The skin has to be reasonably loose and movable, and must be able to slide over the underlying muscle fascia to create folds in the concerned area [Figure 14A and B]. In addition, one can measure the thickness of the subcutaneous fat layer.

\section{DIRECTION OF OPTIMAL INCISIONS}

\section{Face and neck}

Surgical mistakes must be kept to an absolute minimum on the face, where existing folds and wrinkles ${ }^{[36]}$ determine the logical direction of an incision or a fusiform skin excision [Figure 15]. For young patients, mimic movement of the face [Figure 16A and B] or a textbook on facial incisions ${ }^{[2,4,6-8]}$ may serve as a guide for optimal directions.

Incision lines on the neck should run horizontally and preferably inside existing horizontal neck folds. Interestingly, Chinese adolescents frequently have already developed two or three pronounced horizontal neck folds, which should be used. On the other hand, Asian women in general develop nasolabial folds and glabellar frown lines much later than Caucasian women.

Incisions for tracheotomies ${ }^{[36]}$, thyroidectomies, or access to cervical discs should always be done higher up in the lower horizontal neck fold and clear of the jugulum to avoid hypertrophic scarring ${ }^{[5]}$ [Figure $\left.17 \mathrm{~A}\right]$. The "Kocher collar incision" dates back to the late 19 th century ${ }^{[2]}$, when women were wearing high-necked dresses or heavy jewelry. Vertical tracheotomy incisions against the folding lines of the neck are often followed by ugly contracted scars ${ }^{[36]}$ [Figure 17B]. 

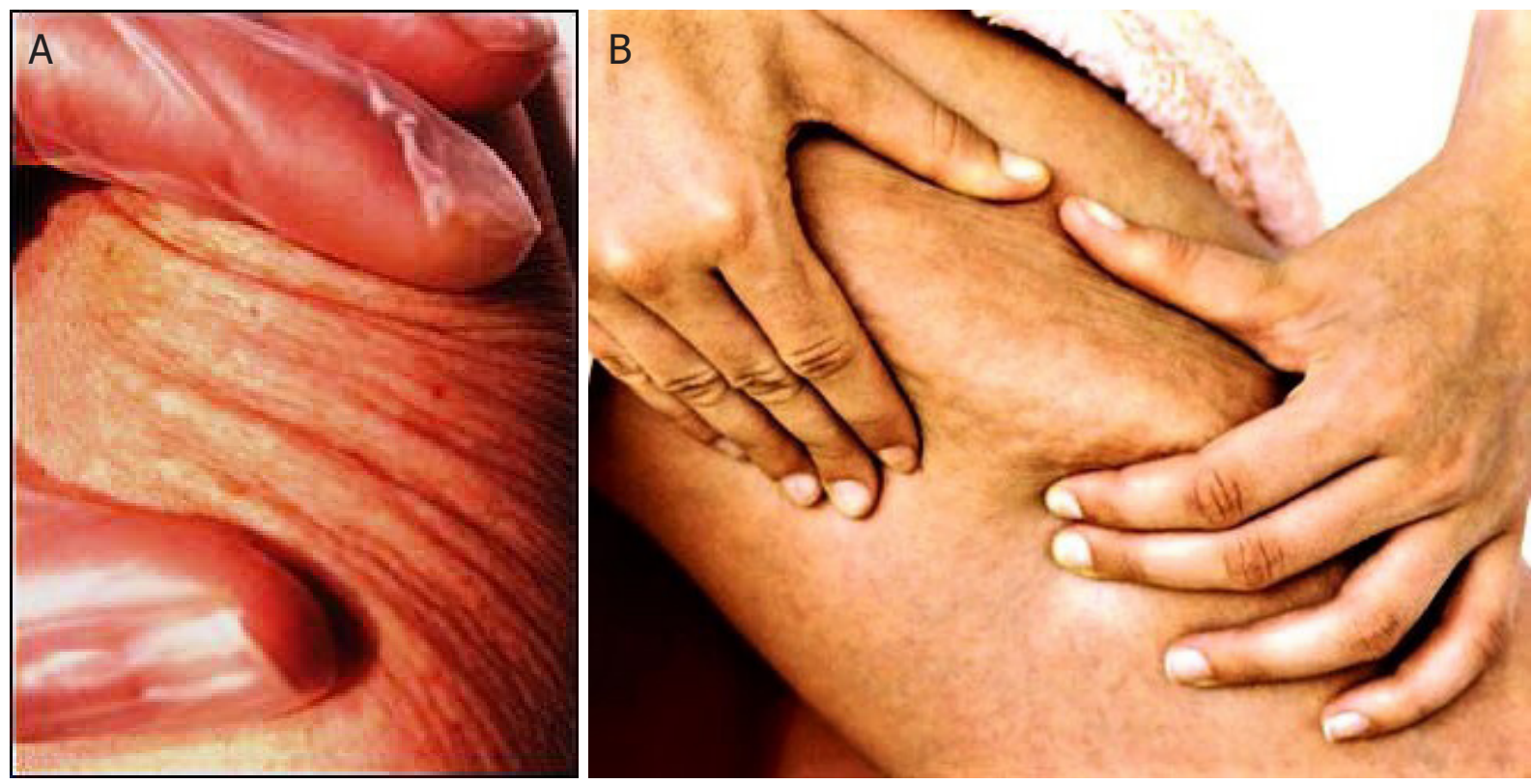

Figure 14. The "pinch test" is an easy way to find the best direction for a surgical incision or excision on the extremities of adults and older patients, but less valuable in children, younger women, and obese patients ( $A$ and $B$ )

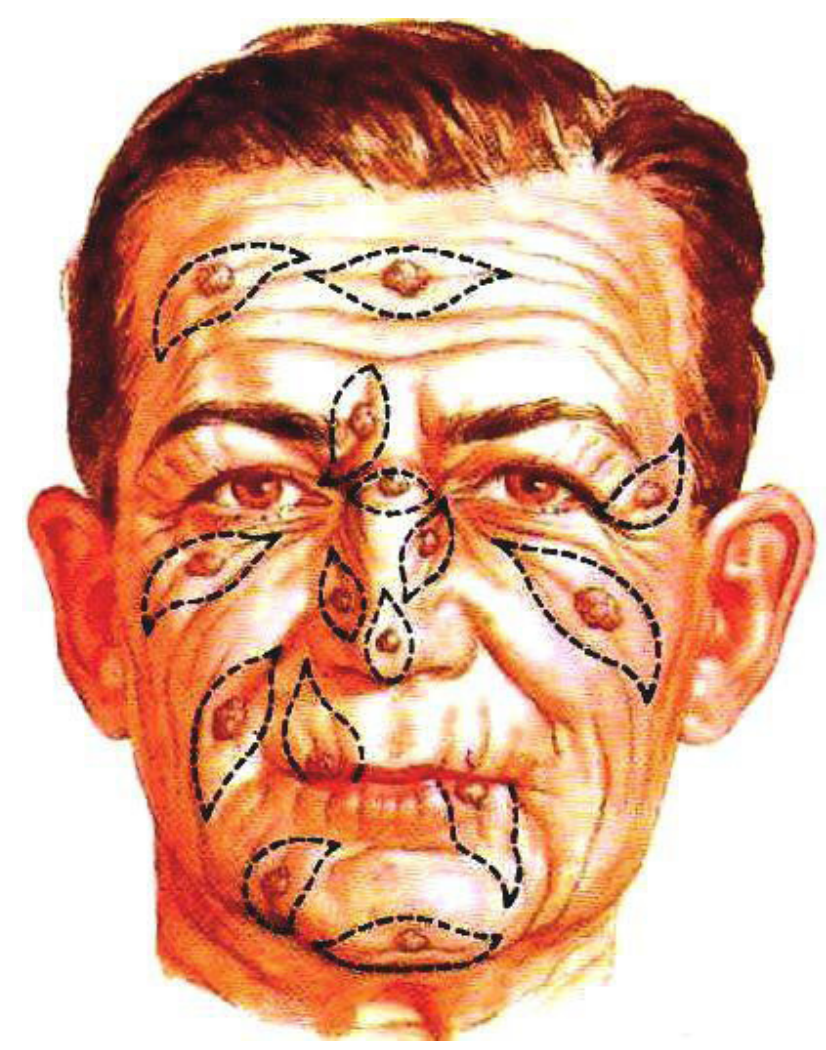

Figure 15. "Main folding lines" on the face and the logical directions of excisions (drawings by Frank H. Netter 1994)

\section{Shoulder and arm}

Striae observed in body builders and in patients with linear focal elastosis or Cushing syndrome all point in one direction [Figure $8 \mathrm{~A}$ ]: horizontal over pectoral and deltoid muscles. Viewed from the front, the 

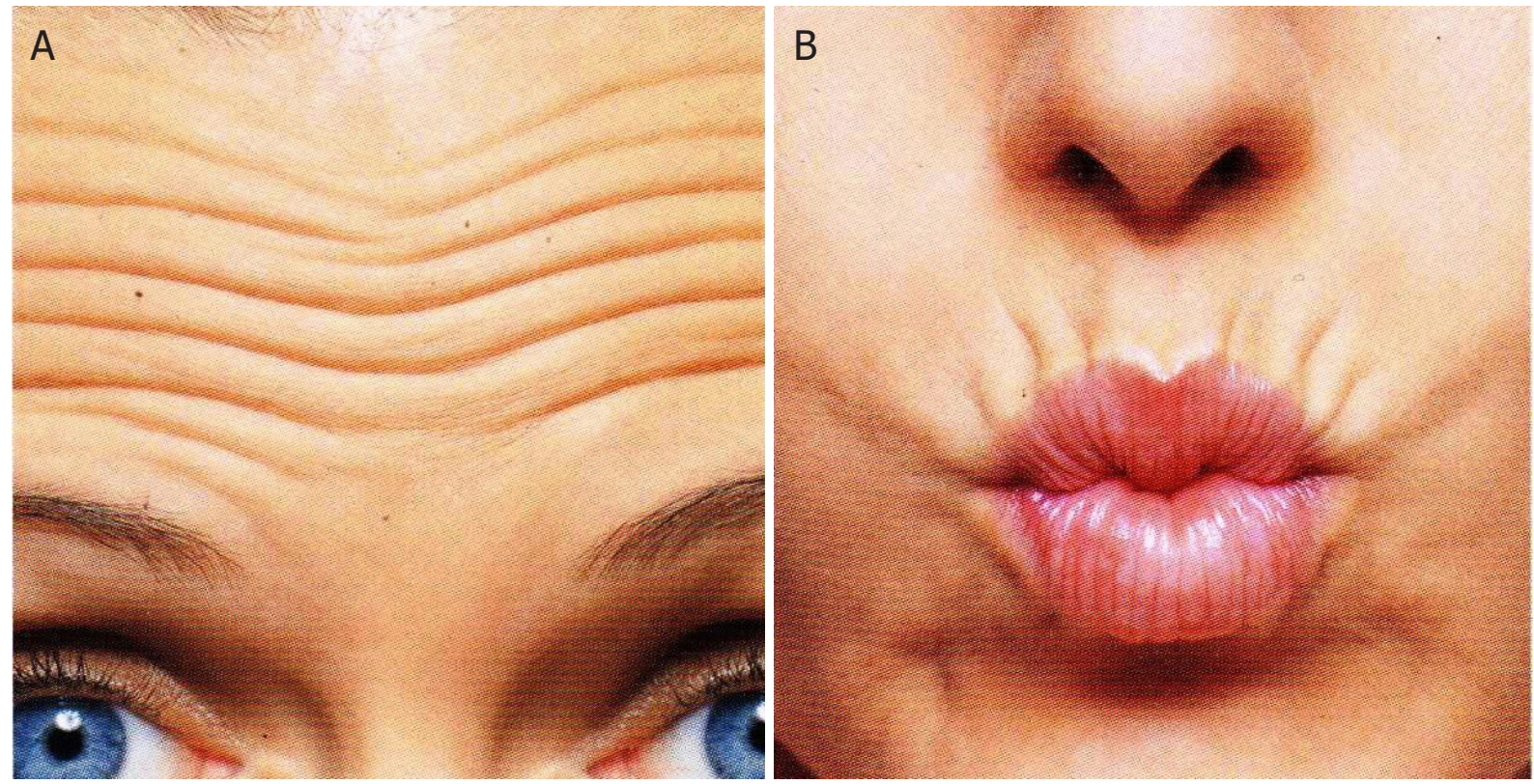

Figure 16. Folds can be formed during facial expressions already in young patients ( $A$ and $B$ )
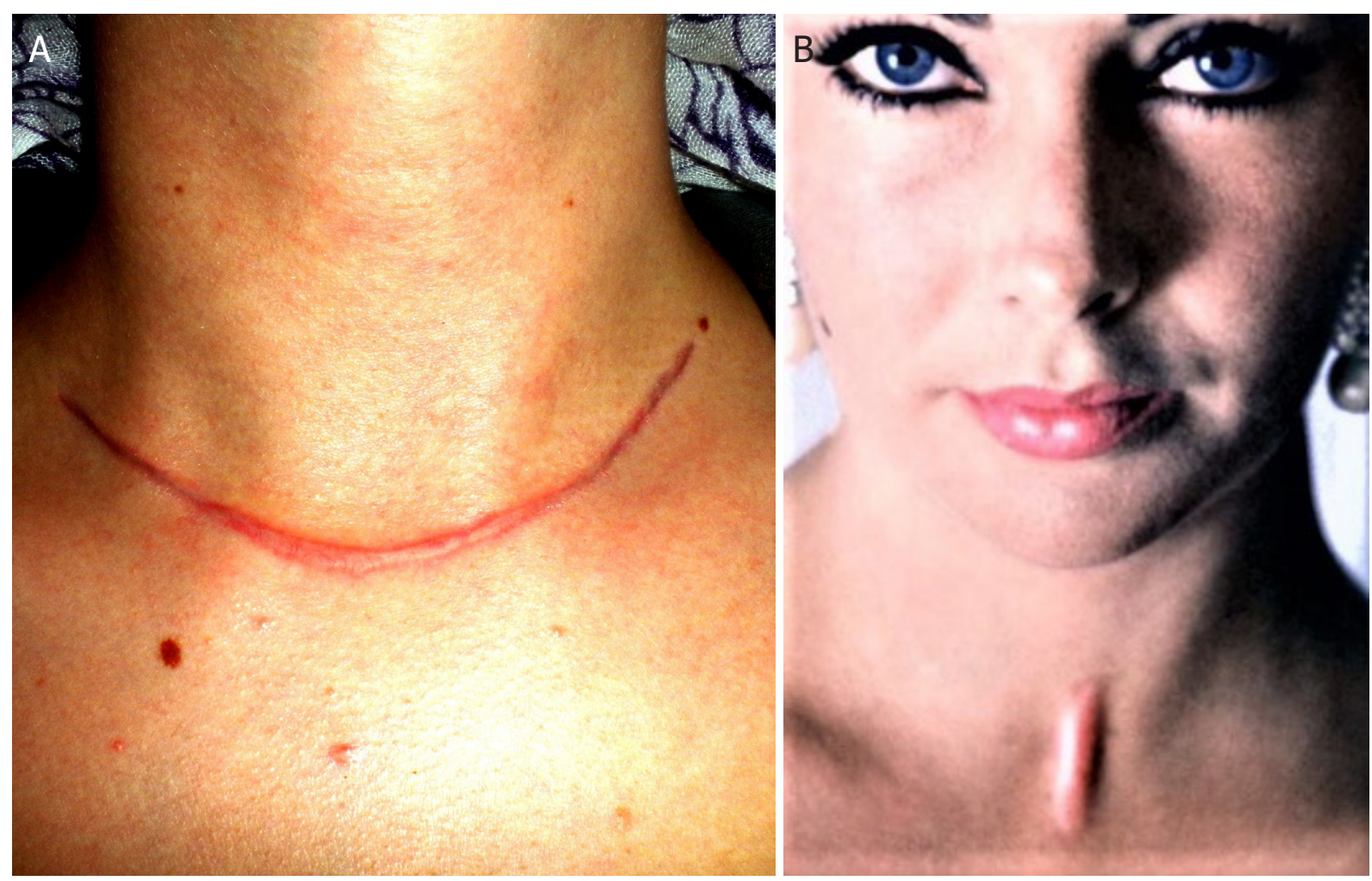

Figure 17. "Kocher's collar incision" over the sternal notch may leave a hypertrophic scar. The thyroid is more easily approached through an incision in the lower cervical fold. Very obvious vertical tracheotomy scar of Elisabeth Taylor (photograph: Douglas Kirkland, 1961) (A and $B$ )

MFL therefore appear vertical between neck and shoulders, but in reality, if viewed from the side, they are virtually horizontal. 

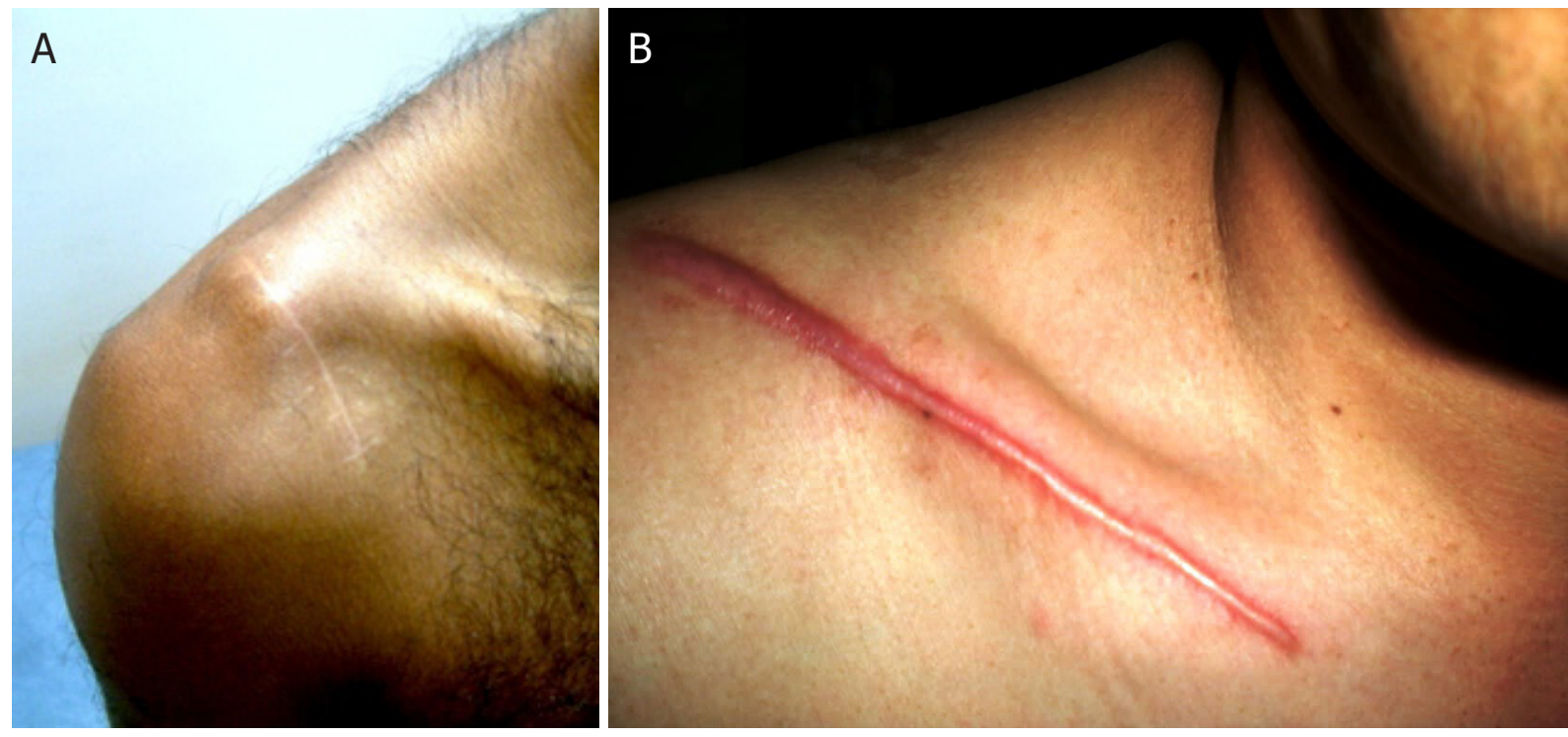

Figure 18. Correct incision in the main folding lines over the shoulder. The typical hypertrophic scar after fixation of a clavicle fracture could have been prevented with a shorter vertical incision in the main folding lines (A and B) (Figure 18B is reproduced with permission from Lemperle et al. ${ }^{[11]}$ )

While fine scars are seen in the direction of folding lines [Figure 18A], wide and hypertrophic scars often develop over the shoulder, over the AC-joint and after open reposition of a clavicle fracture [Figure 18B]. Therefore, in young patients, anterior incisions across the joint and deltoid muscle should be avoided in favor of posterior vertical incisions between axilla and upper arm head.

On the arms, striae do not develop straight vertically, but somewhat obliquely from the anterior axilla to the inner elbow. The tension lines on the upper arm and forearm are not perpendicular to the muscle pull $^{[4]}$ or circumferential, but somewhat oblique and proceed over the joints into the horizontal skin folds. Longitudinal and vertical incisions to expose a bone fracture on the upper arm must be avoided in favor of oblique and semi-circumferential incisions, which will heal inconspicuously.

In planning an incision, the direction of the underlying cutaneous nerves and larger blood vessels must be considered. Larger cutaneous nerves of the extremities may run perpendicular to a recommended incision and must be preserved.

Longitudinal scars on the radial quadrant of the distal forearm skin envelope are typically observed to be wider than those on the ulnar quadrant and have an increased incidence of hypertrophy. The MFL on the forearm appear different in pronation and supination [Figure 14A]. Forearm rotation movements may produce differential skin tensions within the forearm skin envelope, and this may lead to differential scarring patterns ${ }^{[14]}$. Since the forearm is seen either from the inside or outside, incisions should be planned obliquely on the outer side in pronation and on the inner side in supination.

Wound healing in the hand is good in general, especially in the palm. Attention must be paid to the vascularity of the raised flaps to prevent tip necrosis, and palmar incisions should be made inside the natural creases [Figure 19A]. On the dorsum of the hand, horizontal incisions will fall into the "main folding lines", and vertical incisions [Figure 19B] should be avoided or hidden in the ulnar thenar or on the sides of the fingers. 

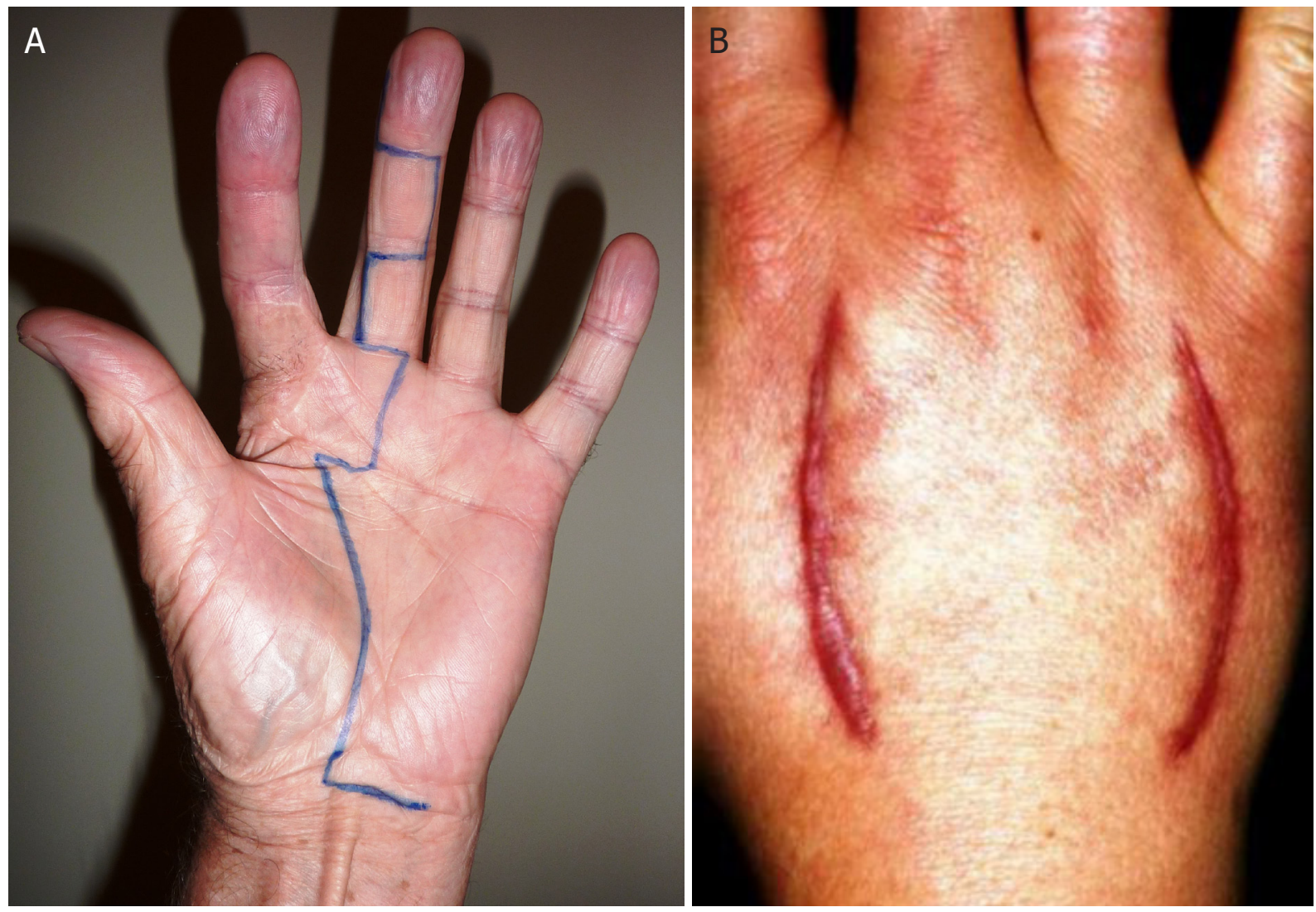

Figure 19. In the volar hand, visible folding lines are used to prevent hypertrophic scars. In the dorsum of the hand, horizontal incisions with preserving nerves and vessels would have produced fine scars (B), and produces fine scars (A and B)

\section{Chest and breast}

Striae over the upper chest develop mainly laterally in a horizontal direction over the pectoral muscle and run more horizontally over the deltoid muscle to the front of the horizontally stretched arm [Figure 8A]. Therefore, the lines on the chest are oblique and become more circular towards the arm, while gravitational forces and movement of the mammary gland may alter this pattern. Women, who have been sleeping on the side for many years, develop "main folding lines" in their décolleté, which originate parallel to the clavicles and run in the form of a " $\mathrm{V}$ " towards the mid-sternum. Therefore, incision lines should be chosen either parallel to the sternum or further caudally, and in the case of skin or breast tumors in women, circumferential at a distance around the areola, i.e., obliquely towards the sternum. Spontaneous keloids, such as the well-known "butterfly keloids", are believed to originate from simple skin pimples and spread horizontally over the sternum often in the direction of the striae.

In performing a sternotomy in adolescents, the median skin incision should be as caudal as possible by sparing the manubrium and undermining the skin up to the sternal notch, since hypertrophic scarring is more pronounced in the upper part [Figure 20A]. Hypertrophic scarring after heart surgery may be prevented in children and young women by performing a wide, half-circumferential, horizontal incision in both inframammary folds ("clamshell incision"); the 4th intercostal space and jugulum can then be reached with the saw by bluntly raising both breasts ${ }^{[37]}$ [Figure 20B].

A lateral incision through the rib cage is always performed horizontally or slightly obliquely parallel to the ribs. In young female patients, the incision should be hidden anteriorly in the respective sub-mammary fold. 

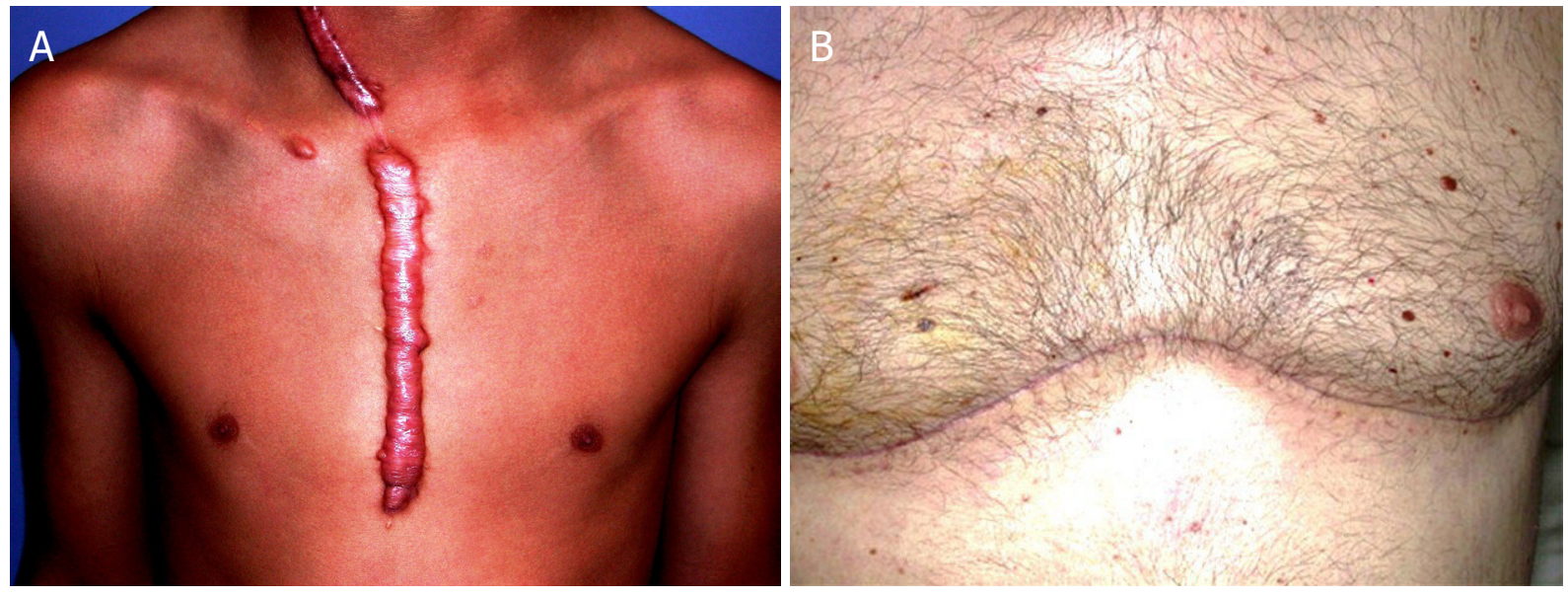

Figure 20. In children and adolescents, open heart surgery may cause severe hypertrophic scarring, which could be avoided by a "clamshell-incision" (A and B) (Figure 20B is reproduced with permission from Lemperle et al. ${ }^{[11]}$ )
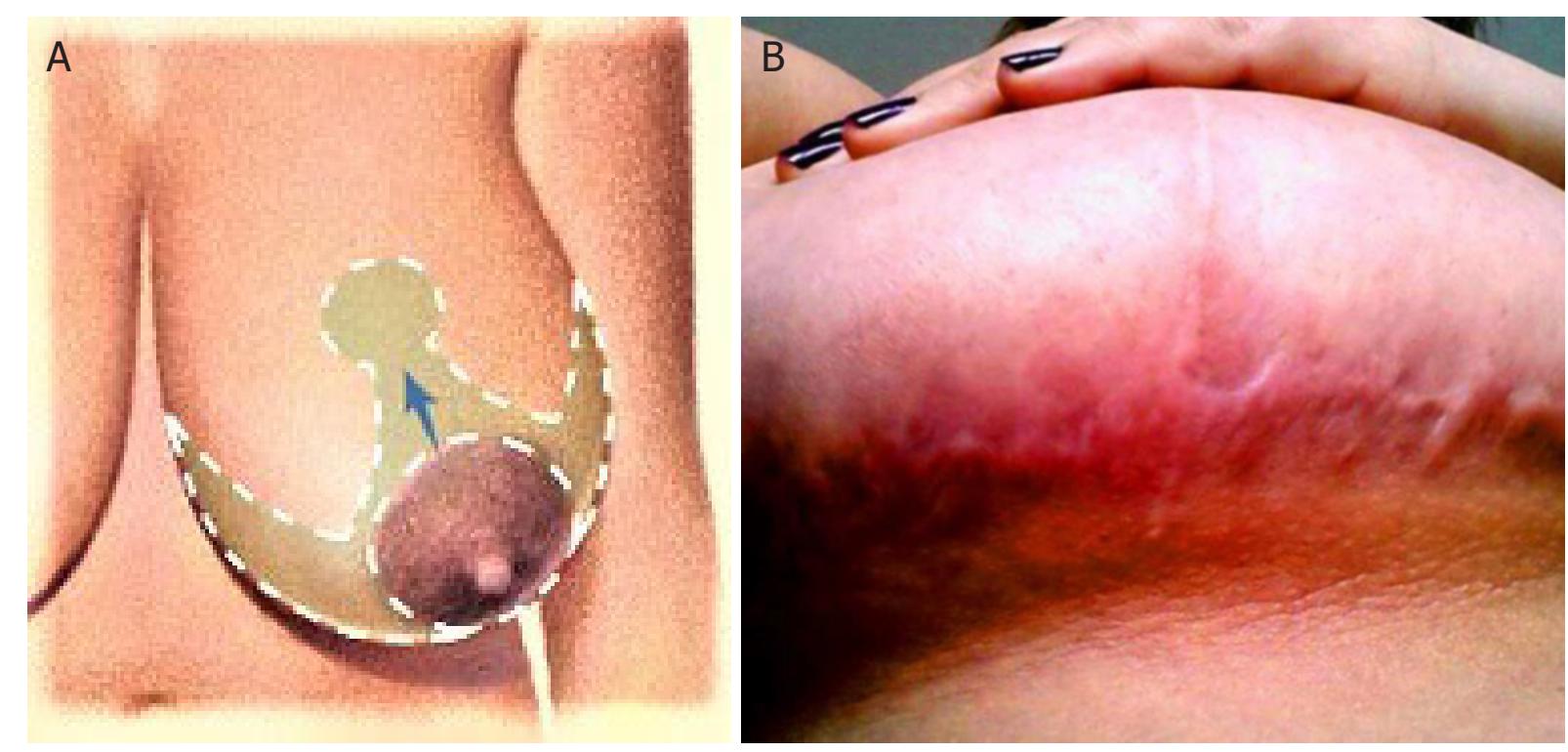

Figure 21. For reduction mammaplasty, the "Wise Pattern" is commonly used: The wound edges of the vertical scar run parallel to the tension lines, but the horizontal edges run perpendicular to the main folding lines. Therefore, the horizontal scar often becomes hypertrophic, whereas the vertical scar appears flat and narrow (A and B) (Figure 21A is a drawing from ADAM Health solutions)

In the breast, striae radiate from the areola outwards [Figure 9B], and therefore, optimal incisions run circumferentially. In augmentation mammoplasty, periareolar horizontal axillary ${ }^{[38]}$, or submammary incisions are performed routinely. After reduction mammoplasty, the often inconspicuous vertical scar may be due to the right angle of the incision line on the Wise pattern [Figure $21 \mathrm{~A}$ ] relative to the real or virtual direction of the radial striae on the breast. The often seen hypertrophy of the horizontal scar in the inframammary fold occurs because 2 wound edges with cross-cut collagen fibers are adapted [Figure 21B].

\section{Abdomen}

There are two ways to open the abdominal cavity in elective general surgery: vertically or transversely. Striae distensae always develop perpendicular to the abdominal skin folding lines [Figure 10B], therefore, skin incisions should be made horizontally wherever possible [Figure 13B]. It has long been shown ${ }^{[39]}$ that wide transverse incisions along the natural folds of the upper abdomen not only yield optimal access to 

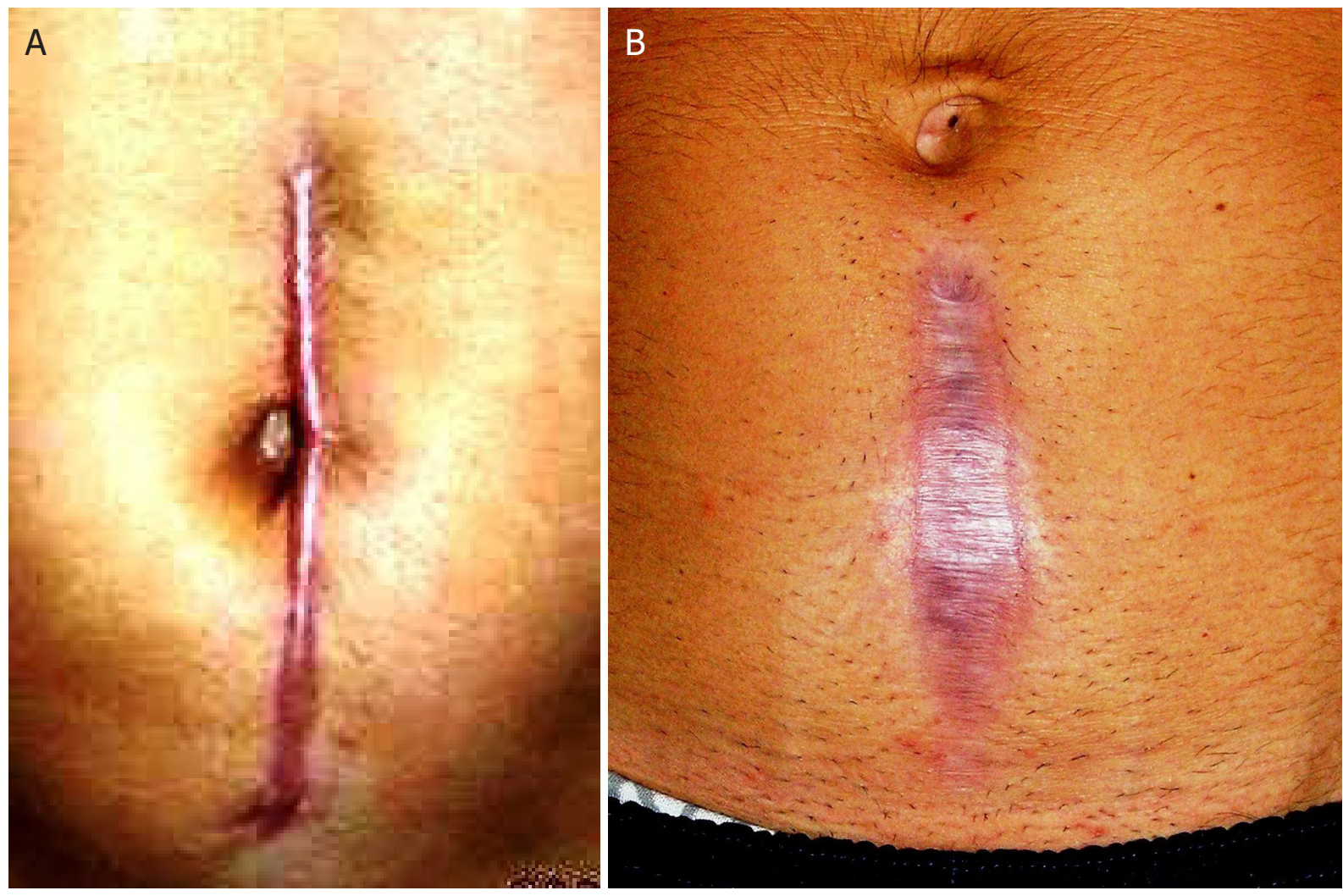

Figure 22. Incisions in abdominal surgery are still performed vertically, i.e., perpendicular to the main folding lines. In adolescents, vertical midline incisions often result in hypertrophic scars, which then widen under triamcinolone injections $(A$ and $B$ )

all organs, but also result in improved healing with significantly less complications than vertical incisions through the linea alba.

A meta-analysis of various clinical studies ${ }^{[39]}$ has postulated that a transverse approach is superior in regard to postoperative complications. This discrepancy between existing recommendations from clinical trials and clinical practice may be explained by a general mistrust of clinical studies or an unwillingness to accept a change for familiar procedures [Figure $22 \mathrm{~A}$ and $\mathrm{B}$ ].

After healing, the mean width of scars was found to be $8.3 \pm 1.4 \mathrm{~mm}$ for midline incisions, while the mean width of scars after transverse incision was $3.3 \pm 1.2 \mathrm{~mm}^{[39]}$. However, general surgeons continue to use the traditional vertical midline incision in $90 \%$ of patients [Figure $23 \mathrm{~A}$ and $\mathrm{B}$ ], despite the additional risk of midline hernias in up to $17 \%$ in elderly obese patients with multi-morbidities ${ }^{[0,41]}$. Rectus abdominis atrophy is a rare complication following transverse incisions.

Unsightly vertical scars after open gallbladder and appendix removal have become obsolete due to modern endoscopic surgery. Old scars are best revised by a longer, but ultimately less obvious, fusiform horizontal excision [Figure $24 \mathrm{~A}$ and $\mathrm{B}$ ].

\section{Back and buttocks}

The simple experiment of approximating the scapulae and extending the arms will reveal many lines in elderly people. This generally vertical pattern in the upper back is altered by the flexion of the head into transverse lines in the neck [Figure 25A and B]. On the contrary, incisions in the back should be performed vertically in the midline or paramedially [Figure 13B], except in women, where they can be hidden 


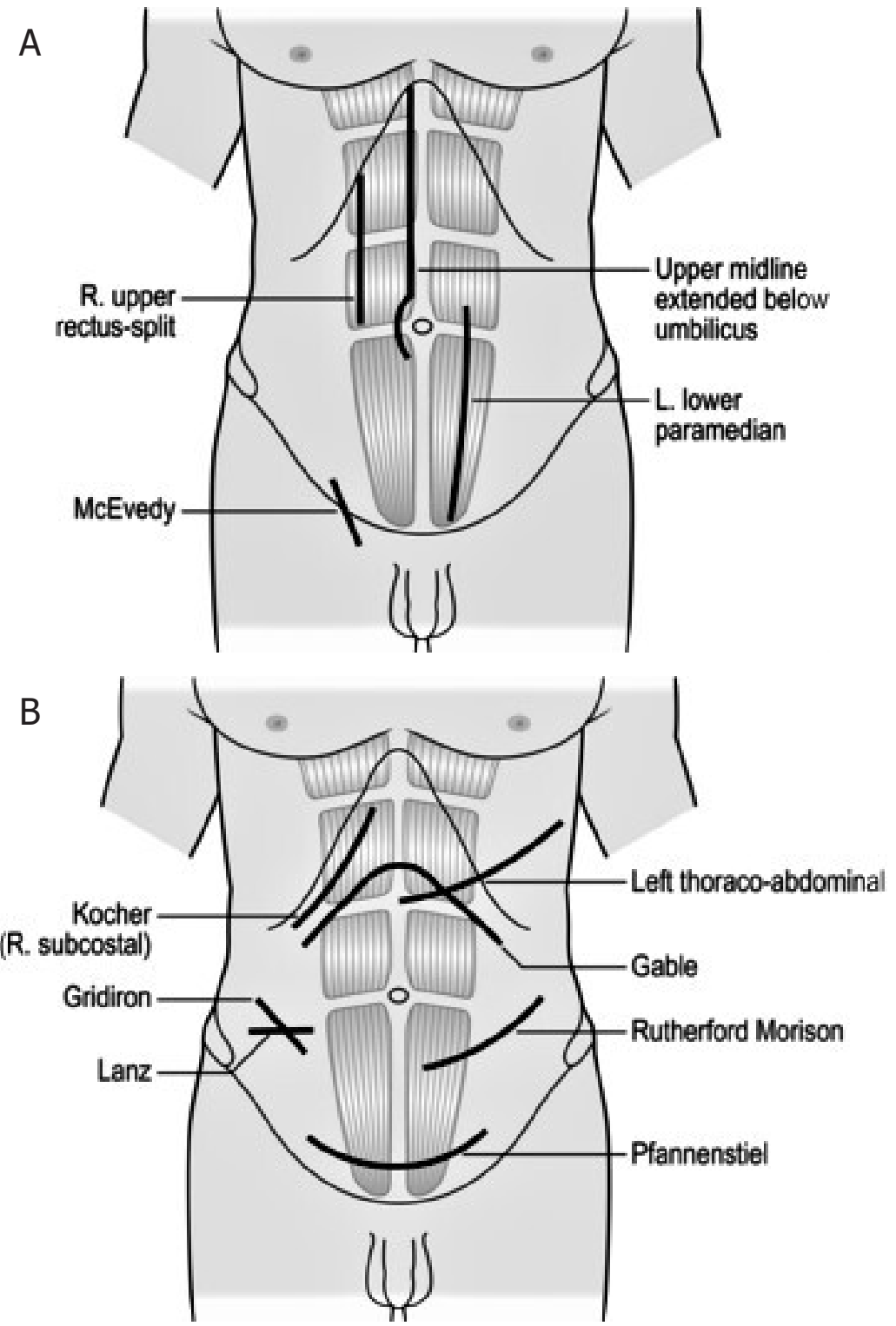

Figure 23. Most abdominal incisions are still perpendicular to the main folding lines, even if some surgeons are using wide horizontal incisions in patients with acute abdominal pain (from iknowledge: R.E. D'Souza and R. Novell: Pancreatectomy and Whipple 2015) (A and $B$ )

beneath a horizontal bra or bikini strap. Elevating a myocutaneous latissimus dorsi flap must be performed according to the defect. The skin island can often be designed horizontally to hide the scar behind a bra. Towards the lateral rib cage, incisions are made obliquely, following the direction of the ribs.

On the back and over the buttocks, the anti-striae lines differ from the Langer and Kraissl lines in a rightangle fashion. Adolescents develop inconspicuous striae in an oblique direction over the hip and gluteus muscle [Figure 10A], it is therefore recommended to consider skin incisions in hip joint surgery in children and adolescents in an oblique direction, but parallel to the fibers of the gluteus maximus between the posterior iliac crest and trochanter major [Figure 26A and B].

Mini-invasive incisions in total hip arthroplasty are a marketing tool for patients refusing a large lateral or anterior incision as a hip prosthesis flag ${ }^{[42]}$. An incision in the direction along the folding lines would produce the best scars. 

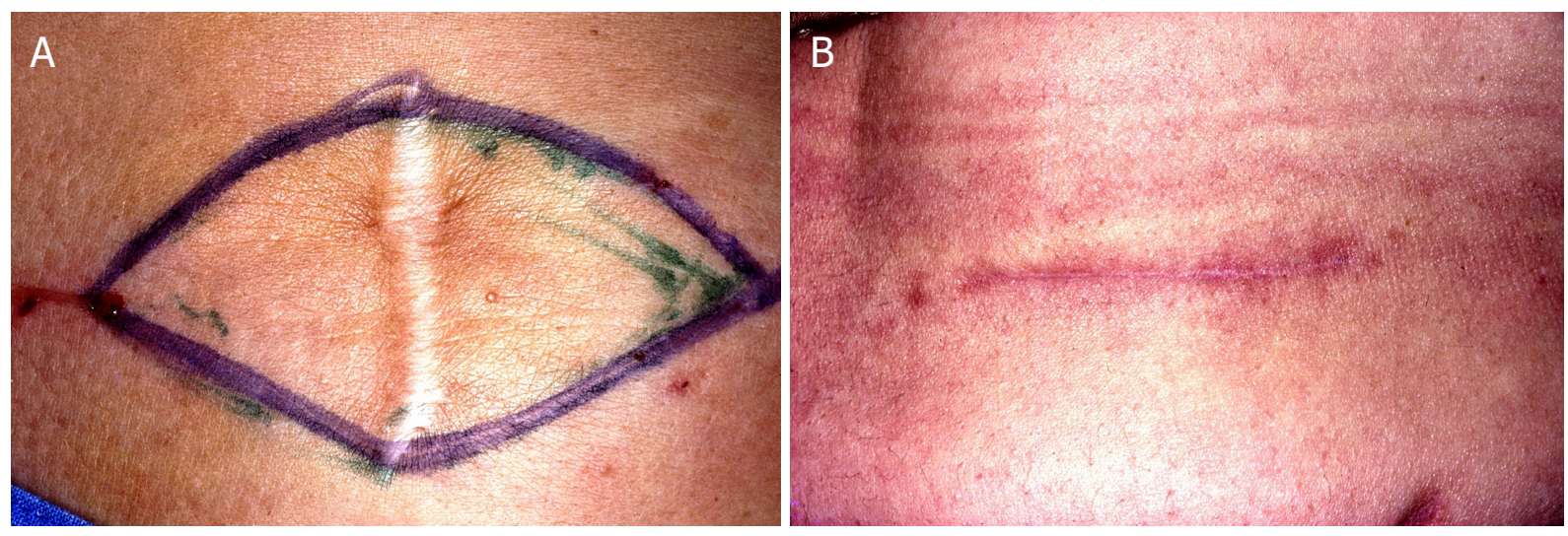

Figure 24. Vertical pararectal hypertrophic scar after cholecystectomy, corrected by horizontal conversion in the main folding lines (A and B) (both figures are reproduced with permission from Lemperle et $a /{ }^{[11]}$ )
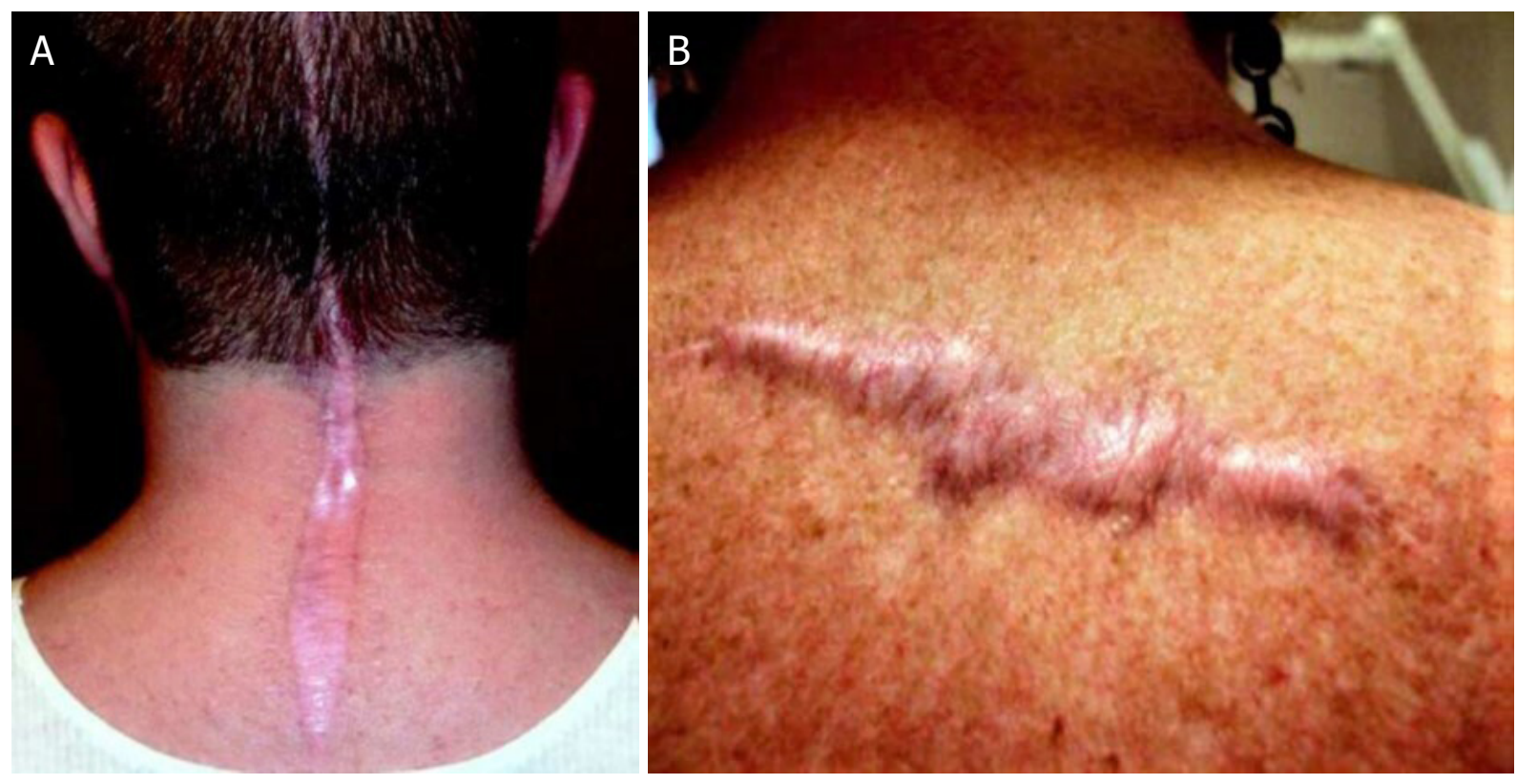

Figure 25. On the dorsal neck, the folding lines run horizontally, but vertically above the scapula. In young patients, horizontal incisions may develop hypertrophy $(A$ and $B)$

\section{Leg and foot}

Inconspicuous striae often develop on the inner thigh and posterior knee in a vertical direction [Figure 11A] and only rarely on the anterior surface of the thigh, where they develop vertically. Above the knee, horizontal folding lines surround the patella and should be used for the excision of suprapatellar fat pads and half-circular incisions either medial or lateral to the patella [Figure 13B], rather than the commonly used vertical incision straight across the knee [Figure 27A and B].

On the lower leg across the calf, striae generally run vertically and in an oblique direction from lateral proximal to medial distal. The skin folds on the lower extremities are analogous to those of the upper limbs. Therefore, oblique incisions from medial proximal to lateral distal over the calf and oblique incisions from proximal posterior to distal anterior over the fibula, are recommended in young patients with selected indications. 

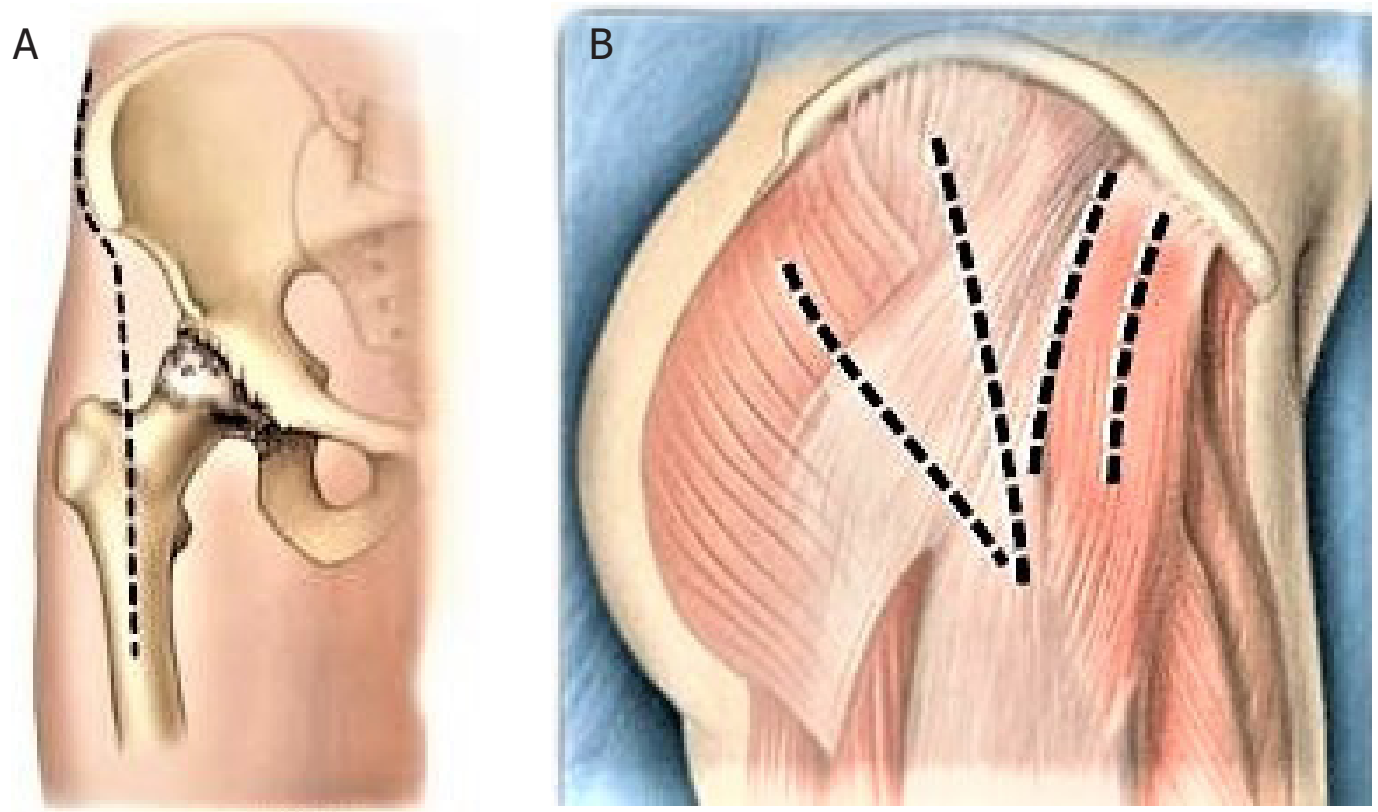

Standard incision

Figure 26. Common incisions for hip surgery run vertically. A more oblique incision parallel to the fibers of the gluteus maximus muscle will result in less conspicuous scars (A and B), (reproduced from Michael Kang, MD, New York, NY)
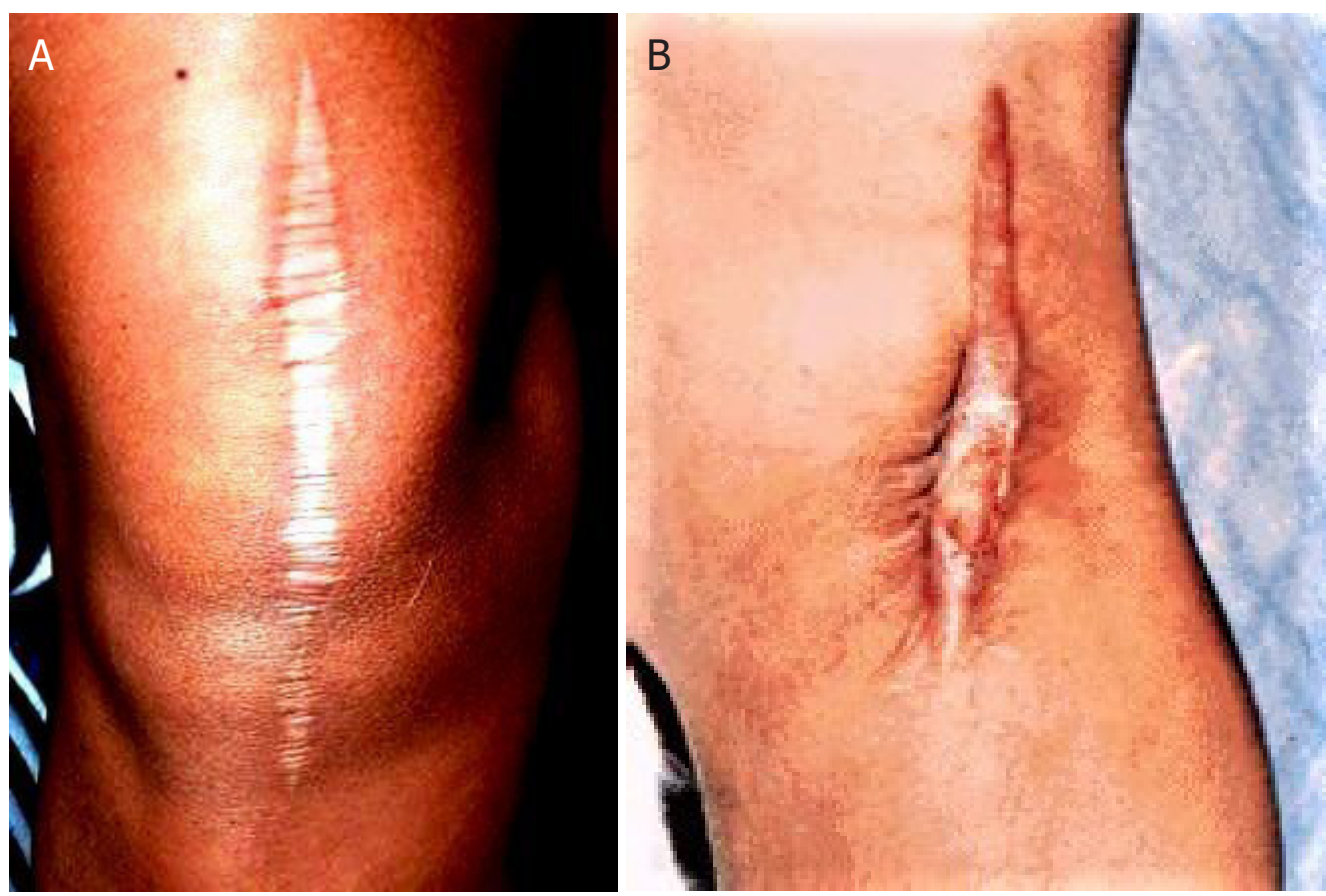

Figure 27. Common vertical scar after knee surgery. The wide opening to the joint after a horizontal incision prevents this conspicuous vertical scar. A vertical cut in the hollow of the knee joint (for the removal of a Baker cyst) should be obsolete since all folds run horizontally $\left(A\right.$ and $B$ ) (Figure $27 \mathrm{~A}$ is reproduced with permission from Lemperle et $a{ }^{\left[{ }^{[11]}\right.}{ }^{\text {) }}$

Since striae do not develop on the feet, "main folding lines" become easily visible during movement of the foot. After bending the foot, the skin can be incised in a horizontal [Figure 28A and B] or oblique direction ${ }^{[43]}$. Both wound edges can then be undermined, bluntly preserving larger nerves and vessels. To 

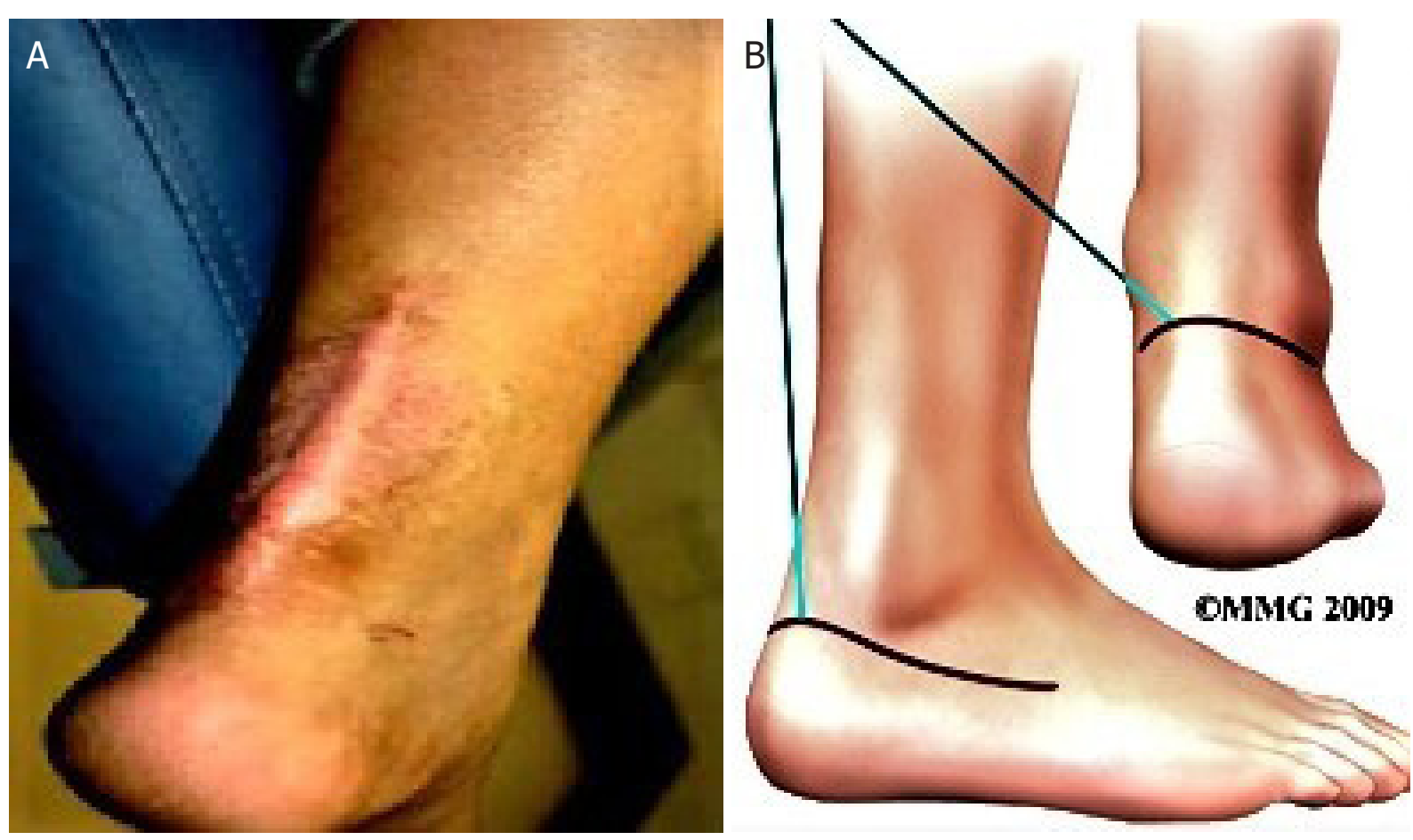

Figure 28. A horizontal approach to a ruptured Achilles tendon as in club foot surgery (Cincinnati approach) will prevent frequently seen hypertrophic scars (A and B)

access joints, tendons or fractures through oblique incisions, no fear for the blood supply is indicated, since the arteries are running in random pattern within the skin. Over the dorsum of the foot, shaped incisions will result in improved healing over straight vertical ones.

\section{CONCLUSION}

In many areas of the body surface, the described "main folding lines" run closely to the Langer lines, with which they are often confused. Langer lines were created by static forces in the skin of cadavers [Figure 29A]. The normal wrinkle lines are produced by dynamic forces acting on the skin of a living person.

If we exclude Langer lines as historic and not primarily intended as recommendation for the direction of skin incisions, we are left with three well-known publications on skin incisions and optimal scarring. Pinkus described MFL produced by "pinching" skin in $1927^{[3]}$, and Kraissl recommended incisions perpendicular to the lines running perpendicular to Langer's lines, especially as they cross joints and facial folds.

In normal folding lines [Figure 29B], the predominant orientation of collagen fibers is parallel to the folds and wrinkles. Collagen bands in scars also form parallel to the wound edges, regardless of scar location. Striae distensae develop perpendicular to the direction of the strongest tension on the skin, and nature reveals that the tension or MFL are perpendicular to the striae.

Surgeons, who have difficulty in identifying skin folds or striae, may use the graphics in this publication as guidance. In elective surgery, most incisions or excisions can be planned in the direction of the MFL [Figure $30 \mathrm{~A}$ and $\mathrm{B}$ ], even when the underlying structures such as ribs and other bones suggest the opposite. Even small incisions for minimally invasive surgery should follow these folding lines ${ }^{[4]]}$. 

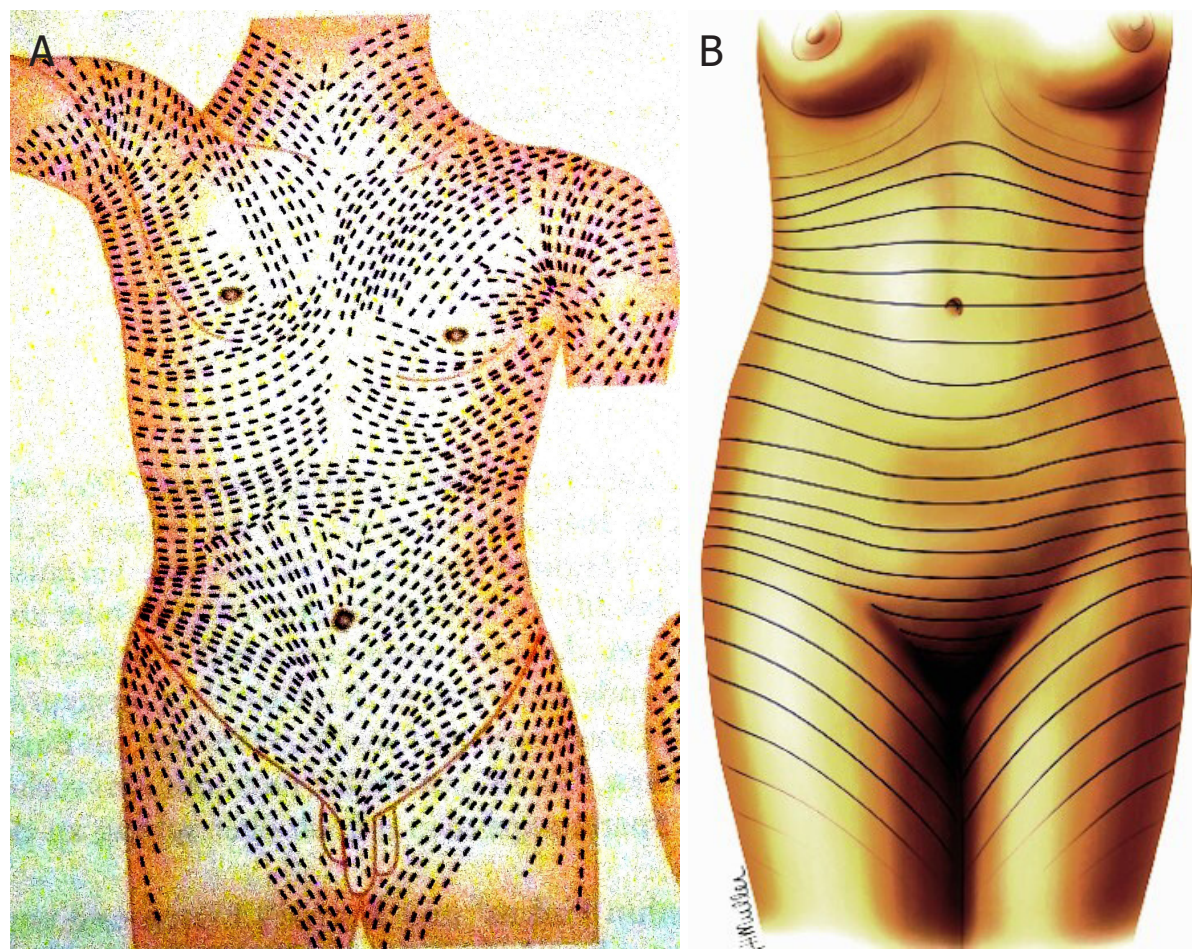

Figure 29. Langer's "cleavage lines" were never meant as guidelines for optimal directions for surgical incisions or excisions. Instead, the use of "main folding lines" is advocated in young patients ( $A$ and B)
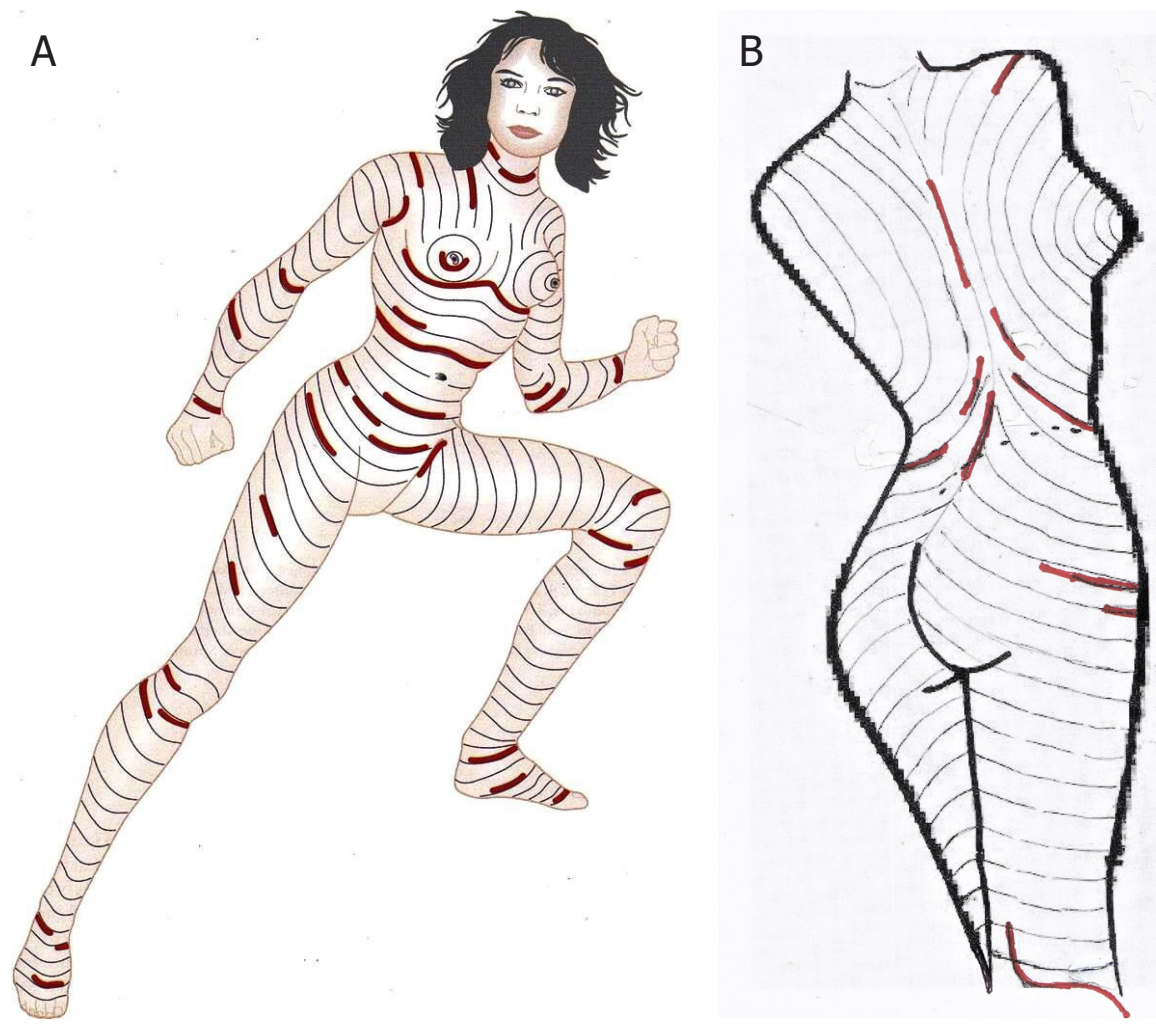

Figure 30. Recommended surgical incisions along the main folding lines (MFL), with sparing of major cutaneous nerves and vessels (A and $B$ ) 

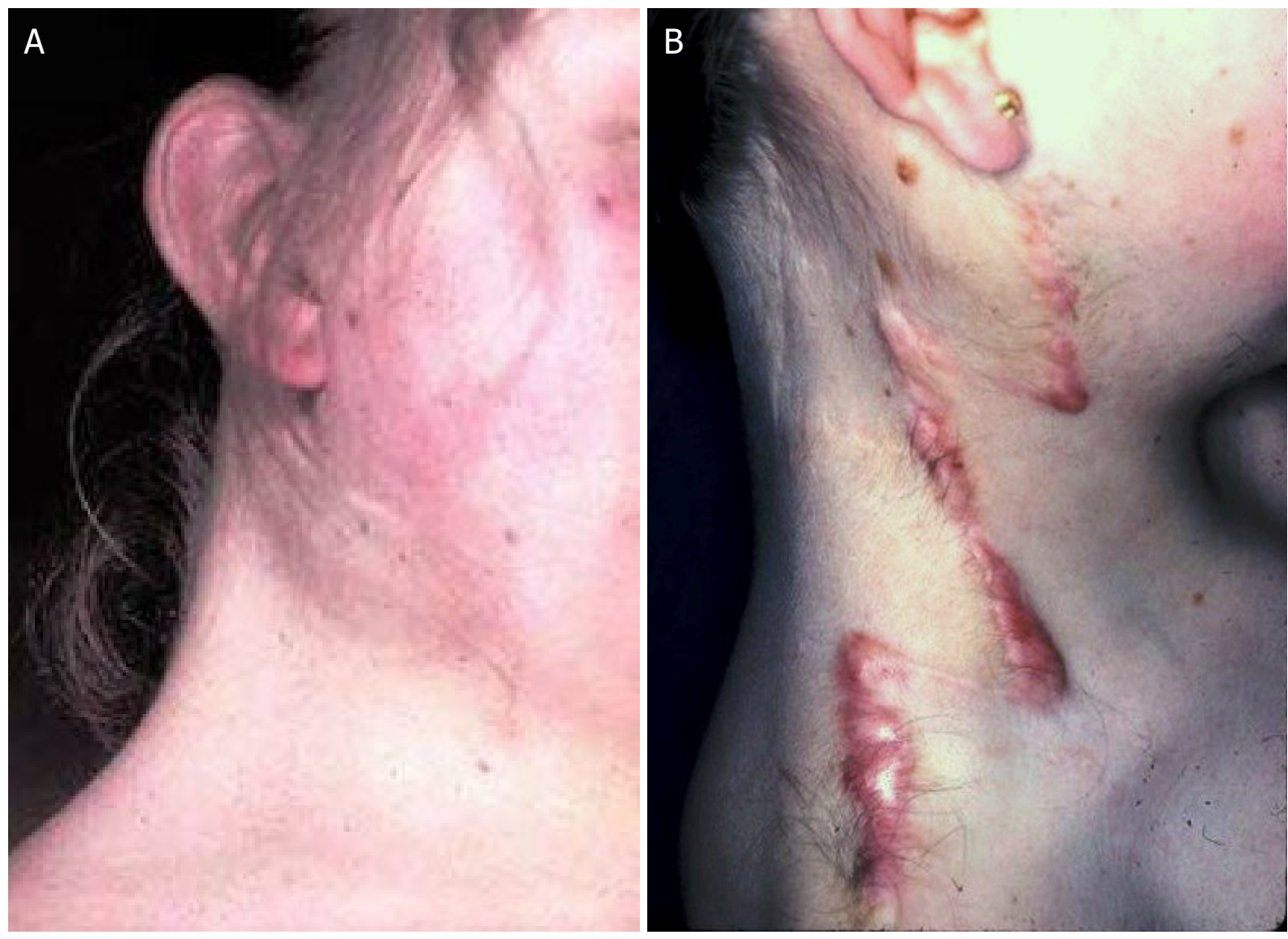

Figure 31. Proof of this recommendation in a "pterygium colli" corrected with two Z-plasties on each side. The scars within the neck's horizontal folding lines are almost invisible; those perpendicular (vertical) to them became hypertrophic (A and B) (Figure 31B is reproduced with permission from Lemperle et $a{ }^{\left[{ }^{[11]}\right.}$ )

Besides paying attention to the least damage to the wound edges, due to excessive spreading and squeezing, the use of electrocautery also for the skin incision seems to cause less scarring compared to the usual scalpel ${ }^{[45]}$. Hypertrophic scarring can also be minimized by making the incision long enough to reduce tension. Plastic surgeons are often asked to correct hypertrophic scars after thyroidectomy [Figure 11B] or cholecystectomy [Figure $24 \mathrm{~B}$ ] in patients with very short scars. Consistent and intense traction on the wound edges during an operation may damage soft tissues, which then react with hypertrophic healing. Small hypertrophic scars should be excised only after "maturation" in the direction of the MFL. The normal skin folds should serve as the main guide for the direction of small fusiform skin excisions, as well as for all longer incisions in selected patients [Figure $31 \mathrm{~A}$ and $\mathrm{B}$ ].

Non-observance of skin tension lines causes widening or hypertrophy of scars. A linear incision develops a wider gap if it occurs parallel to striae rather than transverse to them. "Relaxed skin tension lines" ${ }^{\text {"6-8] }}$ seems to be a confusing expression, while "main folding lines" ${ }^{\text {"[3] }}$ are easier to see, imagine and understand. The simplest rule for making optimal incisions in the most favorable direction is to follow natural wrinkle lines: "Proper incisions come together naturally and improper ones tend to gape" (Th. Kocher 1892 $)^{[2]}$.

\section{DECLARATIONS}

\section{Acknowledgments}

The author thanks Dr. Mayer Tenenhaus, professor of plastic surgery at the University of California, San Diego, for correcting the former manuscript submitted to "Plast. Reconstruct. Surg." ${ }^{[11]}$. 


\section{Author's contributions}

Study concept and data acquisition, data interpretation and manuscript drafting: Lemperle G

\section{Availability of data and materials}

Some of the photographs herein were found in Google Search without mention of any author or copyright; in others, the authors are named if found. Most of the scar photographs originate from my former Department of Plastic Surgery at the Markus-Hospital in Frankfurt am Main, Germany.

\section{Financial support and sponsorship}

None.

\section{Conflicts of interest}

The author declared that there are no conflicts of interest.

\section{Ethical approval and consent to participate}

A written informed consent to participate in research projects was obtained automatically from all patients of the Plastic Surgery Division of Markus-Hospital in Frankfurt am Main, Germany.

\section{Consent for publication}

A written informed consent to participate in possible publications was obtained automatically from all patients of the Markus-Hospital in Frankfurt am Main, Germany.

\section{Copyright}

(c) The Author(s) 2020.

\section{REFERENCES}

1. Langer K. On the anatomy and physiology of the skin. I. The cleavability of the cutis. (Translation from German in 1861). Br J Plast Surg 1978;31:3-8.

2. Kocher T. Textbook of operative surgery. 3rd English ed. London: Adam and Charles Black; 1911. p. 30.

3. Pinkus F. Die Faltung der Haut. In: Pinkus F, editor. Die normale Anatomie der Haut. Jadassohn's Handbuch der Haut und Geschlechtskrankheiten, Vol 1. Berlin: Springer; 1927. pp. 4-76.

4. Kraissl CJ, Conway H. Excision of small tumours of the skin of the face with special reference to the wrinkle lines. Surgery 1949;4:592600 .

5. Kraissl CJ. The selection of appropriate lines for elective surgical incisions. Plast Reconstr Surg 1951;8:1-28.

6. Borges AF, Alexander JE. Relaxed skin tension lines, z-plasties on scars, and fusiform excision of lesions. Brit J Plast Surg 1962;15:242-54.

7. Borges AF. Elective incisions and scar revision. Boston: Little, Brown; 1973. pp. 5-10.

8. Borges AF. Relaxed skin tension lines (RSTL) versus other skin lines. Plast Reconstr Surg 1984;73:144-50.

9. von Torklus D. Atlas orthopädisch-chirurgischer Zugangswege. 4th ed. Auflage Munich: Urban \& Fischer Verlag; 2002.

10. Miller MD, Wiesel SW. Operative Techniques in Sports Medicine \& Surgery. Baltimore: Lippincott Williams \& Wilkins; 2010.

11. Lemperle G, Tenenhaus M, Dieter Knapp D, Lemperle SM. The direction of optimal skin incisions derived from striae distensae. Plast Reconstr Surg 2014;134:1424-34.

12. Wilhelmi BJ, Blackwell SJ, Phillips LG. Langer's lines: to use or not to use. Plast Reconstr Surg 1999;104:208-14.

13. Carmichael SW. The tangled web of Langer's lines. Clin Anat 2014;27:162-8.

14. Russell CJ, Bush JA, Russell GW, Thorlby A, McGrouther DA, et al. Dynamic skin tension in the forearm: effects of pronation and supination. J Hand Surg Am 2009;34:423-31.

15. Courtiss EH, Longacre JJ, deStefano GA, Brizio L, Holmstrand K. The Placement of elective skin incisions. Plast Reconstr Surg 1963;31:31-44.

16. Barile L, Bufalini C. Incisioni chirurgiche in ortopedia e linee di tensione cutanea. Arch Putti Chir Organi Mov 1976;27:127-36.

17. Paul SP, Matulich J, Charlton N. A new skin tensiometer device: computational analyses to understand biodynamic excisional skin tension lines. Sci Rep 2016;6:301.

18. Paul SP. Biodynamic excisional skin tension (BEST) lines: revisiting Langer's lines, skin biomechanics, current concepts in cutaneous surgery, and the (lack of) science behind skin lines used for surgical excisions. J Dermatol Res 2017;2:77-87.

19. Piérard GE, Lapière CM. Microanatomy of the dermis in relation to relaxed skin tension lines and Langer's lines. Am J Dermatopathol 1987;9:219-24. 
20. Viennet C, Bride J, Armbruster V, Aubin F, Gabiot AC, et al. Contractile forces generated by striae distensae fibroblasts embedded in collagen lattices. Arch Dermatol Res 2005;297:10-7.

21. Arem AJ, Kischer CW. Analysis of striae. Plast Reconstr Surg 1980;65:22-9.

22. Alshaiji JM, Handler MZ, Schwartzfarb E, Izakovic J, Schachner LA. Unilateral striae distensae affecting the right axilla in a 16-year-old boy: brief report. Pediatr Dermatol 2014;31:617-8.

23. Cho S, Park ES, Lee DH, Li K, Chung JH. Clinical features and risk factors for striae distensae in Korean adolescents. J Eur Acad Dermatol Venereol 2006;20:1108-13.

24. Basile FP, Volpe A, Basile AR. Striae distensae after breast augmentation. Aesth Plast Surg 2012;36:894-900.

25. Sorensen GW, Odom RB. Axillary and inguinal striae induced by systemic absorption of a topical corticosteroid. Cutis 1976;17:355-7.

26. Rotsztejn H, Juchniewicz B, Nadolski M, Wendorff J, Kamer B. The unusually large striae distensae all over the body. Adv Med Sci 2010;55:343-5.

27. Salter SA, Batra RS, Rohrer TE, Kohli N, Kimball AB. Striae and pelvic relaxation: two disorders of connective tissue with a strong association. J Invest Dermatol 2006;126:1745-48.

28. Watson REB. Stretching the point: an association between the occurrence of striae and pelvic relaxation? J Invest Dermatol 2006;126:1688-9.

29. Ashcroft GS, Mills SJ, Lei K, Gibbons L, Jeong MJ, et al. Estrogen modulates cutaneous wound healing by downregulating macrophage migration inhibitory factor. J Clin Invest 2003;111:1309-18.

30. Cordeiro RC, Zecchin KG, de Moraes AM. Expression of estrogen, androgen, and glucocorticoid receptors in recent striae distensae. Int J Dermatol 2010;49:30-2.

31. Elsaie ML, Baumann LS, Elsaaiee LT. Striae distensae (stretch marks) and different modalities of therapy: an update. Dermatol Surg 2009;35:563-73.

32. Whalen JG, English JC 3rd. Case study on linear focal elastosis. Dermatol Nurs 2006;18:469-71.

33. Jeong JS, Lee JY, Kim MK, Yoon TY. Linear focal elastosis following striae distensae: further evidence of keloidal repair process in the pathogenesis of linear focal elastosis. Ann Dermatol 2011;23:S141-3.

34. Spitz JL. Genodermatoses: a full color clinical guide to genetic skin disorders. 2nd ed. Baltimore: Lippincott, Williams \& Wilkins; 2005.

35. Lemperle G, Holmes RH, Cohen SR, Lemperle SM. A classification of facial wrinkles. Plast Reconstr Surg 2001;108:1735-50.

36. Lim SY, Kwack WG, Kim Y, Lee YJ, Park JS, et al. Comparison of outcomes between vertical and transverse skin incisions in percutaneous tracheostomy for critically ill patients: a retrospective cohort study. Crit Care 2018;22:246.

37. Bedard P, Keon WJ, Brais MP, Goldstein W. Submammary skin incision as a cosmetic approach to median sternotomy. Ann Thoracic Surg 1986;41:339-41.

38. Shrotria S. The peri-areolar incision - gateway to the breast! Eur J Surg Oncol 2001;27:601-3.

39. Halm JA, Lip H, Schmitz PI, Jekeel J. Incisional hernia after upper abdominal surgery: a randomised controlled trial of midline versus transverse incision. Hernia 2009;13:275-80.

40. Bickenbach KA, Karanicolas PJ, Ammori JB, Jayaraman S, Winter JM, et al. Up and down or side to side? A systematic review and metaanalysis examining the impact of incision on outcomes after abdominal surgery. Am J Surg 2013;206:400-9.

41. Heller L, Chike-Obi C, Xue AS. Abdominal wall reconstruction with mesh and components separation. Semin Plast Surg 2012;26:29-35.

42. Leunig M, Hutmacher JE, Ricciardi BF, Impellizzeri FM, Rüdiger HA, et al. Skin crease 'bikini' incision for the direct anterior approach in total hip arthroplasty: a two- to four-year comparative study in 964 patients. Bone Joint J 2018;100-B:853-61.

43. Andermahr J, Jubel A, Elsner A, Schulz-Algie PR, Schiffer G, et al. Die Hautspaltlinien und die Schnittführung bei Fußoperationen. Orthopäde 2007; 36:265-72.

44. Pérez-Bustillo A, González-Sixto B, Rodríguez-Prieto MA. Surgical principles for achieving a functional and cosmetically acceptable scar. Actas Dermosifiliogr 2013;104:17-28.

45. Ismail A, Abushouk AI, Elmaraezy A, Menshawy A, Menshawy E, et al. Cutting electrocautery versus scalpel for surgical incisions: a systematic review and meta-analysis. J Surg Res 2017;220:147-63. 